\title{
Probing the reaction mechanism of spore photoproduct lyase (SPL) via diastereoselectively labeled dinucleotide SP TpT substrates
}

\author{
Linlin Yang ${ }^{\dagger} \S$, Gengjie Lin ${ }^{\dagger} \S$, Degang Liu ${ }^{\dagger}$, Karl J. Dria $^{\dagger}$, Joshua Telser ${ }^{\|}$, and Lei Li ${ }^{\dagger, \ddagger, *}$ \\ tDepartment of Chemistry and Chemical Biology, Indiana University-Purdue University \\ Indianapolis (IUPUI), 402 N Blackford Street, Indianapolis, Indiana, 46202 \\ ¥Department of Biochemistry and Molecular Biology, Indiana University School of Medicine \\ (IUSM), 635 Barnhill Drive, Indianapolis, Indiana 46202 \\ "Department of Biological, Chemical, and Physical Sciences, Roosevelt University, Chicago, \\ Illinois 60605
}

\section{Abstract}

5-thyminyl-5,6-dihydrothymine (commonly called spore photoproduct or SP) is the exclusive DNA photo-damage product in bacterial endospores. It is generated in the bacterial sporulation phase and repaired by a radical SAM enzyme, spore photoproduct lyase (SPL), at the early germination phase. SPL utilizes a special [4Fe-4S] cluster to reductively cleave $S$ adenosylmethionine (SAM) to generate a reactive 5'-dA radical. The 5'-dA radical is proposed to abstract one of the two $\mathrm{H}$ atoms at the $\mathrm{C} 6$ carbon of SP to initiate the repair process. Via organic synthesis and DNA photochemistry, we selectively labeled the $6-\mathrm{H}_{\text {pros }}$ or $6-\mathrm{H}_{\text {proR }}$ position with a deuterium in a dinucleotide SP TpT substrate. Monitoring the deuterium migration in enzyme catalysis (employing Bacillus subtilis SPL) revealed that it is the 6- $\mathrm{H}_{\text {proR }}$ atom of SP that is abstracted by the 5'-dA radical. Surprisingly, the abstracted deuterium was not returned to the resulting $\mathrm{TpT}$ after enzymatic catalysis, an $\mathrm{H}$ atom from the aqueous buffer was incorporated into TpT instead. This result questions the currently hypothesized SPL mechanism which excludes the involvement of protein residue(s) in SPL reaction, suggesting that some protein residue(s), which is capable of exchanging a proton with the aqueous buffer, is involved in the enzyme catalysis. Moreover, evidence has been obtained for a possible SAM regeneration after each catalytic cycle; however, such a regeneration process is more complex than currently thought, with one or even more protein residues involved as well. These observations have enabled us to propose a modified reaction mechanism for this intriguing DNA repair enzyme.

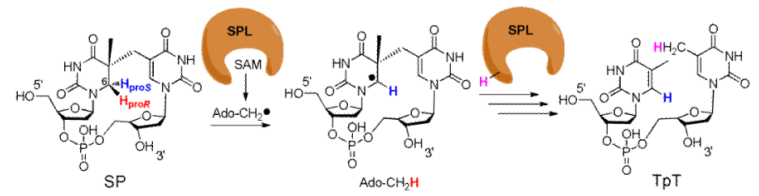

\footnotetext{
*lilei@iupui.edu .

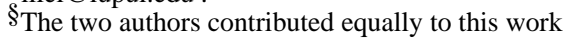

Supporting Information Available: Syntheses and characterizations of deuterated SP substrates, TpT photochemistry, ESI-MS spectra of the isolated SAM, comparison EPR spectra of Aquifex aeolicus Fd1 and reduced SPL. This information is available free of charge via the internet at http://pubs.acs.org. 


\section{Introduction}

Spore-forming bacteria are responsible for a number of serious diseases in humans, including botulism (Clostridium botulinum), gas gangrene and food poisoning (Clostridium perfringens), tetanus (Clostridium tetani), and anthrax (Bacillus anthracis). ${ }^{1}$ At the sporulation phase, these bacteria are extremely resistant to normal sterilization means such as heat, oxidizing chemicals, and UV or gamma irradiation. For instance, some Bacillus spores can be 100-fold more resistant to UV light than the corresponding vegetative cells. ${ }^{2,3}$ As spores contain a minimum amount of proteins and a complete genomic DNA, the ability to protect their DNA against external damage is suggested to be the key for their survival. The spore DNA is bound by a group of DNA binding proteins named small acid-soluble proteins (SASPs) that block the access of toxic chemicals to the genomic DNA. ${ }^{4}$ Furthermore, this SASP-DNA interaction changes the DNA photoreaction pattern. Instead of generating pyrimidine cyclobutane dimers, the spore DNA photoreaction produces a different dimer, 5-thyminyl-5,6-dihydrothymine (commonly called spore photoproduct or $\mathrm{SP})$ as the exclusive UV damage product. Spores express a specific enzyme, spore photoproduct lyase (SPL), to effectively reverse the SP dimer at the early germination phase, allowing resumption of their normal life cycle (Scheme 1). This unique DNA photochemistry and the associated efficient damage repair in spores are suggested to be the keys for their extreme UV resistance; however the reaction mechanism of both processes is not well-understood. ${ }^{5-13}$

SP was first discovered about half a century ago; ${ }^{14}$ the mechanism regarding its photoformation was largely unclear. ${ }^{5,15}$ As shown in Scheme 1, as a result of SP formation, the SP C5 carbon becomes chiral, and the C6 carbon becomes pro-chiral, possessing two hydrogen atoms with unknown origins. We hypothesized that one of the C6 hydrogen atoms is transferred from the methyl group of the $3^{\prime}-\mathrm{T}$, while the other one is retained from the original thymine at that position. To test this assumption, we synthesized two TpT isotopologs: a $d_{3}-\mathrm{TpT}$ dinucleotide containing a $\mathrm{CD}_{3}$ moiety in the $3^{\prime}-\mathrm{T}$ and a $d_{4}-\mathrm{TpT}$ dinucleotide with the four carbon-bound protiums in the $5^{\prime}$-T replaced by deuteriums (Scheme 2). After UV radiation, a deuterium was transferred exclusively to the 6- $\mathrm{H}_{\mathrm{proS}}$ position when $d_{3}$-TpT was used as the starting material (Scheme 2A). The migrated atom was a protium when $d_{4}$-TpT was employed (Scheme 2B). These observations, together with the previous NMR study which determined the R configuration of the C5 carbon at the 5'$\mathrm{T},{ }^{16}$ enabled us to propose a new mechanism for the SP photoreaction. ${ }^{17}$

SP is repaired by the spore photoproduct lyase (SPL) enzyme at the early bacterial germination phase. ${ }^{5,18,19} \mathrm{SPL}$ is a member of the so-called radical SAM superfamily, which was defined by the characteristic CXXXCXXC motif, ${ }^{20}$ although recent evidence suggests that other three-cysteine motifs still facilitate the same radical chemistry. ${ }^{18,21,22}$ The three cysteine residues serve as ligands for each of three irons in the $[4 \mathrm{Fe}-4 \mathrm{~S}]$ cluster, with the fourth iron being coordinated by the $S$-adenosylmethionine (SAM) in a bi-dentate manner, with its amino and carboxylate moieties serving as the fourth and fifth ligands to the cluster. ${ }^{23}$ The cluster at its +1 oxidation state donates an electron to SAM to cleave its C-S bond, generating a $5^{\prime}$-deoxyadenosyl radical $\left(5^{\prime}\right.$-dA $\left.\bullet\right)$ This 5 '-dA radical catalyzes highly diverse biochemical reactions in animals, plants and microorganisms, including steps in metabolism, DNA/RNA modification, and the biosynthesis of vitamins, coenzymes and many antibiotics. ${ }^{18-22,24-36}$

SPL catalyzes SP repair using a direct reversal strategy via a radical mechanism. The currently hypothesized SPL mechanism is shown in Scheme 3: the 5'-dA radical generated via SAM reductive cleavage first abstracts one of the two hydrogen atoms on the C6 carbon of SP to form a C6 radical and 5'-dA. This C6 radical fragments into one thymine and a 
thymine radical, which takes the hydrogen back from 5'-dA to yield the repaired $\mathrm{T}$ (The thymine methyl radical in Scheme 3 is likely to delocalize to the aromatic ring; the current drawing is a simplified model to facilitate discussion). Such a hypothesis was first suggested by Begley and Mehl based on a modeling study. ${ }^{12}$ By attaching a phenylthiol moiety at the C6 position of a bipyrimidine analog, clean formation of dimethylthymine was observed under radical generating conditions, indicating that SPL initiates the SP repair by abstracting one of the 6-H atoms. Broderick et.al. later tritiated thymine at either the $\mathrm{CH}_{3}$ (at $\mathrm{C} 5$ ) or the C6 position and introduced the labeled thymine into a pUC18 vector. ${ }^{11}$ After UV radiation to generate SP in the plasmid DNA, the SP containing plasmid was treated with SPL. Tritium was found to be incorporated into SAM when the C6 position of thymine was tritiated. In contrast, no tritium was found in $\mathrm{SAM}$ when the $\mathrm{CH}_{3}$ group was labeled. Such observations supported a proposal that the SPL abstracts the $\mathrm{H}$-atom from the $\mathrm{C} 6$ carbon to initiate the SP repair. The abstracted $\mathrm{H}$-atom ended up in SAM, leading to a hypothesis that SAM is regenerated after each reaction cycle, as shown in Scheme 3.

A careful analysis of this experimental approach reveals that it was based on the assumption that the 6-H atom from thymine remains at that position after SP formation, which is proved correct from our recent photochemical studies. ${ }^{17}$ However, we were intrigued by the fact that no tritium was detected in SAM when the thymine methyl group was tritiated as an $\mathrm{H}$ atom from the $\mathrm{CH}_{3}$ group of $3^{\prime}-\mathrm{T}$ migrates to the $6-\mathrm{H}_{\text {pros }}$ position of $\mathrm{SP}$ after the photoreaction, as illustrated by Scheme 2. Additionally, the C6 carbon in SP has two $\mathrm{H}$ atoms and is pro-chiral. Given that enzymatic reactions are usually highly stereoselective, then if the reaction is initiated by $\mathrm{H}$-abstraction at $\mathrm{C} 6$, which $\mathrm{H}$-atom is taken?

We therefore prepared several dinucleotide SP TpT substrates with the two 6-H atoms of SP selectively labeled via DNA photochemistry. ${ }^{17}$ Using the resulting TpT isotopologs to probe the SPL reaction, we are able not only to answer the questions raised above, but also demonstrate that the currently hypothesized SPL mechanism needs significant revision.

\section{Experimental Section}

\section{Materials and Methods}

Unless otherwise stated all solvents and chemicals used were of commercially available analytical grade. They were purchased from Sigma, Fisher, or VWR and used without further purification except the 3,5-bis(4-chlorobenzoyl)-2-deoxy- $\alpha$-D-ribofuranosyl chloride (9), which was purchased from ShangHai Hanhong Chemical Co., Ltd at Shanghai, P. R. China. All reactions were carried out using oven or flame-dried glassware under a nitrogen atmosphere in distilled solvents. Dichloromethane and pyridine were distilled over calcium hydride. Purification of reaction products was carried out by flash chromatography using silica gel (Dynamic Adsorbents Inc, 32-63 $\mu \mathrm{m}$ ). For TLC analysis, precoated plates (w/h F254, Dynamic Adsorbents Inc, $0.25 \mathrm{~mm}$ thick) were used. The ${ }^{1} \mathrm{H}$ and ${ }^{13} \mathrm{C}$ NMR spectra were obtained on a Bruker $500 \mathrm{MHz}$ NMR Fourier transform spectrometer. NMR spectra were recorded in the following solvents: deuterated chloroform $\left(\mathrm{CDCl}_{3}\right)$, with residual chloroform ( $\delta 77.2 \mathrm{ppm}$ for ${ }^{13} \mathrm{C}$ NMR) and TMS ( $\delta 0 \mathrm{ppm}$ for ${ }^{1} \mathrm{H}$ NMR), deuterated methanol ( $\delta 3.31 \mathrm{ppm}$ for ${ }^{1} \mathrm{H}$ NMR and $\delta 49.1 \mathrm{ppm}$ for ${ }^{13} \mathrm{C}$ NMR) or deuterated methyl sulfoxide (DMSO- $d_{6}$ ), with residual methyl sulfoxide $\left(\delta 2.50 \mathrm{ppm}\right.$ for ${ }^{1} \mathrm{H}$ NMR and $\delta 39.5$ ppm for ${ }^{13} \mathrm{C}$ NMR) taken as the standard. The chemical shifts in NMR spectra were reported in parts per million (ppm). Mass spectrometry (MS) analysis was obtained using Agilent 1100 series LC/MSD system with Electrospray Ionization (ESI). The TpT photoreaction was carried out using a Spectroline germicidal UV sterilizing lamp (Dual-tube, $15 \mathrm{w}$, intensity: $1550 \mathrm{uw} / \mathrm{cm}^{2}$ ) with samples $\sim 5 \mathrm{~cm}$ from the lamp. 
All DNA-modifying enzymes and reagents were purchased from Fermentas Life Sciences (Glen Burnie, MD). B. subtilis strain 168 chromosomal DNA was purchased from the ATCC (ATCC 23857D). Oligonucleotide primers were obtained from Integrated DNA Technologies (Coralville, IA). E. Coli BL21(DE3) and expression vector pET-28a were purchased from Novagen (Madison, WI). The construct containing the SPL gene was coexpressed with plasmid pDB1282, which was a generous gift from Prof. Squire Booker at the Pennsylvania State University. 5'-deoxyadenosine (5'-dA) and $S$-adenosylmethionine (SAM) was purchased from Aldrich and used directly without further purification. 5 Prime Perfectpro* Nickel nitrilotriacetic acid (Ni-NTA) resin was purchased from Fisher Scientific. All other buffers and chemicals were of the highest grade available.

The protein purification as well as the enzyme reactions were carried out under an inert atmosphere using a Coylab anaerobic chamber (Grass Lake, MI) with the $\mathrm{H}_{2}$ concentration around 3\%. Product analysis was conducted using a Waters (Milford, MA) breeze HPLC system with a 2489 UV/Visible detector and an Agilent 1100 LC-MS system under both a positive and negative ionization mode. Sonic disruption of $E$. coli cells was conducted by a Fisher Scientific* Model 500 Digital Sonic Dismembrator. DNA sequencing was performed by the Indiana University Nucleic Acid Core Facility at IU School of Medicine.

Construction of the of SPL expression vector-The splB gene was cloned from the B. subtilis chromosomal DNA (strain 168) using the synthetic oligonucleotide primers 5'GCAAGTGCGAATTCCAGAACCCATTTGTTCC-3' (containing an EcoRI site) and 5'GCAAGCTCAAGCTTTTAAGTGAAATATTCAAT-5' (containing a HindIII site) and amplified by standard PCR techniques. The resulting PCR product was digested by EcoRI/ HindIII and ligated into the same sites in pET-28a, which harbors an in-frame N-terminal hexahistidine tag to facilitate protein purification. The construct was transformed into $E$. coli $10 \mathrm{G}$ chemically competent cells purchased from Lucigen Corporation (Middleton, WI) for isolation and amplification of the $s p l B$ gene-containing plasmid DNA. The resulting vector was named SPL-pET28 and co-transformed with a pDB 1282 vector into E. coli BL21(DE3) obtained from Stratagene (La Jolla, CA) for protein overexpression. The pDB 1282 vector confers ampicillin resistance and harbors an $E$. coli operon that is involved in the biosynthesis of $\mathrm{FeS}$ clusters and is thus believed to facilitate incorporation of the $\mathrm{FeS}$ clusters into the apoprotein of SPL. ${ }^{21,37}$

Expression of SPL-A single colony of transformed cells was used to inoculate $5 \mathrm{~mL}$ of LB medium containing the appropriate antibiotics to maintain selection for the plasmid. The cultures were grown to saturation at $37^{\circ} \mathrm{C}$ with vigorous shaking and then used to inoculate $1 \mathrm{~L}$ of antibiotics containing LB medium. Once the cells reached early log phase $\left(\mathrm{OD}_{600} \approx\right.$ 0.8 ), the temperature was decreased to $16^{\circ} \mathrm{C}$ and the expression of the genes induced by addition of isopropyl $\beta$-D-thiogalactopyranoside (IPTG) to a final concentration of $0.1 \mathrm{mM}$. The expression was allowed to proceed for $12 \mathrm{~h}$ and the cells harvested by centrifugation (5000 rpm for $15 \mathrm{~min}$ at $4{ }^{\circ} \mathrm{C}$ ). The medium was decanted and the cell pellet stored at -20 ${ }^{\circ} \mathrm{C}$.

Purification of SPL protein-To purify SPL, the cell pellet from $1 \mathrm{~L}$ of culture was resuspended in $30 \mathrm{~mL}$ of lysis buffer containing $25 \mathrm{mM}$ Tris, $300 \mathrm{mM} \mathrm{NaCl}, 10 \mathrm{mM}$ imidazole, $5 \mathrm{mM} \beta$-mercaptoethanol, $1 \mathrm{mM} \mathrm{PMSF}$ and $10 \%$ glycerol (pH 7.0). The cells were lysed by sonication on ice and centrifuged at $17000 \mathrm{rpm}$ for $20 \mathrm{~min}$ at $4{ }^{\circ} \mathrm{C}$. The supernatant was loaded onto a $1.5 \mathrm{~mL} \mathrm{Ni-NTA-agarose} \mathrm{column} \mathrm{and} \mathrm{moved} \mathrm{into} \mathrm{a} \mathrm{Coy}$ anaerobic chamber. The rest of the protein purification steps were carried out under an inert atmosphere. The column was washed with 10 volumes of the buffer containing $50 \mathrm{mM}$ Tris, $300 \mathrm{mM} \mathrm{NaCl}, 20 \mathrm{mM}$ imidazole and 10\% glycerol (pH 7.0). The tagged SPL protein was eluted with the same buffer but containing $250 \mathrm{mM}$ imidazole. The eluted protein was 
yellow-brown colored and was determined to be essentially homogeneous by SDS-PAGE gel stained with Coomassie blue. The proteins were dialyzed three times against a buffer containing $25 \mathrm{mM}$ Tris, $300 \mathrm{mM} \mathrm{NaCl}$ and $10 \%$ glycerol (pH 7.0). The protein was then aliquoted into $50 \mu \mathrm{l}$ PCR tubes, flash-frozen in liquid $\mathrm{N}_{2}$ and stored at $-80{ }^{\circ} \mathrm{C}$.

Protein, iron, and sulfide assays-Routine determinations of protein concentrations were done by the method of Bradford, ${ }^{38}$ using bovine serum albumin and bovine gamma globulin as protein standards. Protein concentrations were calibrated on the basis of the absorption of aromatic residues at $280 \mathrm{~nm}$ in the presence of $6 \mathrm{M}$ guanidine hydrochloride using the method of Gill and von Hippel. ${ }^{39}$ Iron content was determined using $o$ bathophenanthroline (OBP) under reductive conditions after digestion of the protein in $0.8 \%$ $\mathrm{KMnO}_{4}$ and $1.2 \mathrm{M} \mathrm{HCl}$ as described by Fish. ${ }^{40}$ Iron standards were prepared from commercially available ferric chloride and ferrous ammonium sulfate. Sulfide assays were carried out using the method described by Beinert. ${ }^{41}$

[4Fe-4S] cluster reconstitution-The as-isolated SPL $(300 \mu \mathrm{L})$ was taken out of the $-80^{\circ} \mathrm{C}$ freezer and allowed to thaw inside the Coy chamber at ambient temperature. To this protein solution, $5 \mu \mathrm{L}$ of $100 \mathrm{mM}$ DTT was added followed by the addition of $\mathrm{FeCl}_{3}$ and $\mathrm{Na}_{2} \mathrm{~S}$ to a final concentration of $100 \mathrm{M}$ each. The SPL was then incubated anaerobically for $1 \mathrm{~h}$ at ambient temperature. In the presence of $10 \%$ glycerol, the protein was fairly stable and little precipitate was observed after these treatments. Under rare circumstances, centrifugation of the resulting protein solution was needed to remove the precipitated protein; otherwise, the protein can be used directly for the activity assays. For the samples prepared for iron and sulfur content analyses, desalting columns (Thermo Scientific Zeba Spin Desalting Column from Fisher Scientific) were applied to remove the un-reacted small inorganic ions before measurements were conducted.

Preparation of deuterated SP TpT_As shown in Chart 1, four different SP TpTs were prepared in this report with deuterium being selectively incorporated into different positions. SPs were prepared in two different ways: organic synthesis or DNA photochemistry. ${ }^{17,42}$ Among the four SPs shown in Chart 1, compound (1) was prepared via organic synthesis and compounds $\mathbf{2}, \mathbf{3}$ and $\mathbf{4}$ were prepared via photochemistry using correspondent deuterated TpT dinucleotides as the starting material. The experimental details in SP syntheses can be found in either the supporting information or our previous publication. ${ }^{17,43}$ The formed SP TpTs were isolated by a Waters semi-prep HPLC column, characterized via NMR and ESIMS spectroscopes and kept for enzyme activity studies.

SPL activity determination-The SPL protein after cluster re-constitution was used immediately to assay the SPL activity. Typically, a reaction mixture contained $30 \mathrm{M} \mathrm{SPL,} 3$ $\mathrm{mM}$ correspondent SP TpT substrate, $300 \mu \mathrm{M}$ SAM, and $2 \mathrm{mM}$ DTT in a final volume of $400 \mu \mathrm{L}$ of buffer containing $25 \mathrm{mM}$ Tris- $\mathrm{HCl}, 300 \mathrm{mM} \mathrm{NaCl}$ and $10 \%$ glycerol at $\mathrm{pH}$ 7.0. Sodium dithionite (final concentration $1 \mathrm{mM}$ ) was added as a reductant to initiate the enzyme reaction. The reactions were carried out under anaerobic conditions at ambient temperature for various periods of time. Under the conditions of the assay, the formation of TpT was linear with time for up to $15 \mathrm{~min}$. At each time point, $90 \mu \mathrm{L}$ of the solution was taken out to an Eppendorf tube and quenched by $10 \mu \mathrm{L}$ of $3 \mathrm{M} \mathrm{HCl}$. Other quenching methods such as heating at $100{ }^{\circ} \mathrm{C}$ for 5 minutes or flash-freezing by liquid $\mathrm{N}_{2}$ were also tested and no difference on SPL activity was observed by these quenching means. After removing the protein residues via centrifugation at $15,000 \mathrm{rpm}$ for $20 \mathrm{~min}$, the resulting supernatants were loaded onto HPLC. The yielded TpT from each sample was integrated from HPLC chromatographs, calibrated and plotted against reaction time to generate the reaction rate. 
SPL activity examined in the absence of external reductant-The SPL protein after cluster re-constitution as described above was reduced by $1 \mathrm{mM}$ sodium dithionite for $30 \mathrm{~min}$. Excess inorganic ions were removed via a Thermo Scientific Zeba Spin Desalting Column. SP TpT and SAM were then added to a final concentration of $3 \mathrm{mM}$ and $100 \mathrm{M}$ ( 3 -fold of SPL) respectively to initiate the SP repair reaction. At different time points, $50 \mu \mathrm{L}$ of the solution was taken out and quenched by $5 \mu \mathrm{L}$ of $3 \mathrm{M} \mathrm{HCl}$ and the resulting solution analyzed by HPLC.

SPL activity examined in $\mathrm{D}_{\mathbf{2}} \mathrm{O}$ - To investigate the involvement of the water solvent in SPL reaction, the reconstituted SPL protein was exchanged into a $\mathrm{D}_{2} \mathrm{O}$ buffer containing 25 $\mathrm{mM}$ Tris- $\mathrm{HCl}, 300 \mathrm{mM} \mathrm{NaCl}$ and $5 \% d_{8}$-glycerol at $\mathrm{pH} 7.0$ via an Amicon Ultra- $0.5 \mathrm{~mL}$ Centrifugal Filter column (Millipore, MA). SP TpT (1), SAM and DTT were subsequently added from the stock solution prepared using the same $\mathrm{D}_{2} \mathrm{O}$ buffer and the reaction were quenched by $\mathrm{HCl}$ at various reaction times. The resulting solution was analyzed by LC-MS.

Solvent isotope effect determination-To minimize the impact of the handling process on the enzyme activity, the SPL enzyme was exchanged into a $\mathrm{H}_{2} \mathrm{O}$ buffer under identical conditions employed in $\mathrm{D}_{2} \mathrm{O}$ experiments. SP TpT (1), SAM and dithionite were subsequently added to initiate the SP repair reaction and the reaction quenched by $\mathrm{HCl}$ at various reaction times and analyzed via HPLC. The solvent isotope effect was determined by comparing the rate obtained in $\mathrm{H}_{2} \mathrm{O}$ with that determined in $\mathrm{D}_{2} \mathrm{O}$.

Reaction isotope effect determination in $\mathbf{D}_{\mathbf{2}} \mathbf{O}$-The SPL enzyme was exchanged into $\mathrm{D}_{2} \mathrm{O}$ buffer as described above followed by addition of SAM and sodium dithionite. SP compound $\mathbf{1}$ or $\mathbf{4}$ was subsequently added and the reaction allowed proceeding for varying times, then quenched by $\mathrm{HCl}$ and analyzed by HPLC. The isotope effect was calculated via comparing the reaction rates determined with compound $\mathbf{1}$ and $\mathbf{4}$ as substrate respectively.

Examination of deuterium incorporation into SAM-The incorporation of deuterium from $d_{4}$-SP TpT (4) into SAM was examined via a literature procedure with some modifications. ${ }^{26}$ Briefly, the assay employed $1 \mathrm{mM} \mathrm{4,} 200 \mu \mathrm{M}$ SAM, and $150 \mu \mathrm{M}$ SPL in a $300 \mu \mathrm{L}$ buffer which contained $25 \mathrm{mM}$ Tris- $\mathrm{HCl}, 300 \mathrm{mM} \mathrm{NaCl}, 1 \mathrm{mM}$ DTT and $10 \%$ glycerol at $\mathrm{pH}$ 7.0. The reaction was initiated by addition of dithionite to a final concentration of $1 \mathrm{mM}$ and allowed to proceed at ambient temperature for $3 \mathrm{~h}$. All substrate added was consumed at this point as proved by HPLC analysis, suggesting that the SPL enzyme catalyzed at least 6 turnovers. $100 \mu \mathrm{L}$ of the reaction solution was taken out and quenched by one of several methods: addition of $10 \mu \mathrm{L} 3 \mathrm{M} \mathrm{HCl}$; addition of $10 \mu \mathrm{L} 10 \%$ SDS; heating at $100{ }^{\circ} \mathrm{C}$ for 30 minutes. The SAM released by the former two methods was analyzed by LC-MS. Thermal decomposition of SAM by the last method leads to the formation of $5^{\prime}$-methylthioadenosine (MTA), ${ }^{44}$ which was confirmed by co-injection of an authentic sample bought from the Sigma-Aldrich Corporation with the SAM decomposition product. Any deuterium incorporated into SAM is expected to be retained in the resulting MTA, which was analyzed by LC-MS using the protocol developed previously in mechanistic studies of lysine 2,3-aminomutase (LAM). ${ }^{45,46}$

HPLC assay for product analysis-Chromatography was performed at room temperature with detection at $268 \mathrm{~nm}$ using an Agilent Zorbax reverse-phase C-18 column $(3.5 \mu \mathrm{M}, 4.6 \times 50 \mathrm{~mm})$. The column was equilibrated in $50 \mathrm{mM}$ triethylammonium acetate (TEAA), $\mathrm{pH} 6.5$, and compounds were eluted with an ascending gradient $(0-25 \%)$ of buffer B which is composed of 50\% buffer A and 50\% acetonitrile at a flow rate of $1 \mathrm{~mL} /$ min. Under this gradient, SP TpT was eluted at $6.0 \mathrm{~min}, 5^{\prime}$-dA at $7.8 \mathrm{~min}$ and TpT at 10.2 $\mathrm{min}$. The identity of the products was confirmed by co-injection of respective authentic 
samples as well as by LC-MS spectrometry. The area of the product peak was determined after subtraction of the baseline from the $t=0$ chromatograph and the amounts of 5 '-dA and $\mathrm{Tp} \mathrm{T}$ formed were determined by reference to standard curves constructed with authentic samples.

LC-MS assay for product analysis-Low resolution LC-MS analyses were conducted via an Agilent 6130 Quadrupole LC/MS spectrometer coupled to an Agilent 1100 series chromatography system. The high resolution LC-MS analyses were conducted via an Agilent 6520 Accurate Mass Q-TOF LC/MS coupled to an Agilent 1200 series capillary chromatography system. The high resolution mass data analysis and formula assignments were conducted using Agilent MassHunter software. Due to potential contamination to the LC/MS system, the TEAA buffer system used above was aborted and instead a $0.1 \%$ formic acid in $\mathrm{H}_{2} \mathrm{O}$ was utilized as solvent $\mathrm{A}$ and $0.1 \%$ formic acid in acetonitrile as solvent $\mathrm{B}$. The Waters X-bridge ${ }^{\mathrm{TM}}$ OST C18 column $(2.5 \mu \mathrm{M}, 4.6 \times 50 \mathrm{~mm})$ was used for the low resolution LC-MS analysis. The column was equilibrated in solvent $\mathrm{A}$, and compounds were eluted with an ascending gradient $(0-17 \%)$ of solvent $B$ at a flow rate of $1 \mathrm{~mL} / \mathrm{min}$ in $17 \mathrm{~min}$. Under this gradient, SAM was eluted at $2.1 \mathrm{~min}, \mathrm{SP}$ TpT at $5.5 \mathrm{~min}, 5^{\prime}-\mathrm{dA}$ at $7.1 \mathrm{~min}$ and $\mathrm{TpT}$ at $8.2 \mathrm{~min}$. The mass signals in positive and negative ion mode were monitored simultaneously in the experiments. For the high resolution mass analysis, an Agilent Poroshell 300SB C18 $(5 \mu \mathrm{M}, 1.0 \times 75 \mathrm{~mm})$ column with a flow rate of $0.25 \mathrm{~mL} / \mathrm{min}$ using a gradient of 0 to $30 \%$ solvent B over 20 minutes was used and only mass signals under the negative ion mode were monitored.

UV-visible spectroscopy-UV-visible spectra were recorded using UV-Mini 1240 Spectrophotometer in combination with the associated data manager software package. UVvisible spectroscopy was determined using the same buffer described above, which contained $25 \mathrm{mM}$ Tris- $\mathrm{HCl}, 300 \mathrm{mM} \mathrm{NaCl}$ and $10 \%$ glycerol at $\mathrm{pH}$ 7.0. $300 \mu \mathrm{L}$ SPL solution was transferred to a UV cuvette with a 1-cm length path (purchased from Fisher Scientific and modified by the glass shop at IU Bloomington) plugged with a rubber septum in the Coy chamber and the UV spectra taken outside the glovebox using a Shimadzu UVMINI-1240 spectrometer. The cluster reduction was achieved by addition of sodium dithionite to a final concentration of $2 \mathrm{mM}$ in the anaerobic chamber.

EPR experiments-Continuous wave (CW) EPR spectra were recorded on a modified Varian spectrometer at $35 \mathrm{GHz}$ ("Q"-band) and $2 \mathrm{~K}^{47}$ The as-isolated SPL ( $400 \mu \mathrm{M}, 3.1$ iron/protein) was reduced with $2 \mathrm{mM}$ dithionite inside the anaerobic chamber for $60 \mathrm{~min}$ and placed into the EPR tube and immediately frozen in liquid $\mathrm{N}_{2}$. The sample remained frozen for EPR measurements. Under the experimental conditions employed here, which lead to "rapid-passage" effects, ${ }^{48} 35 \mathrm{GHz}$ EPR spectra are observed in the dispersion mode and appear as absorption lineshapes, rather than the standard absorption mode detection and first derivative presentation. Digital derivatives were taken to allow conventional presentation. EPR simulations were performed using the program QPOW, ${ }^{49}$ as modified by J. Telser.

\section{Results \\ SPL protein expression and purification}

The splB gene was cloned into a pET 28a vector which introduces of a hexahistidine tag to facilitate protein purification. Ni-NTA chromatography afforded SPL as a dark-brown solution when purified under a strictly inert atmosphere. The purity of the protein was checked by SDS-PAGE gel to be $>95 \%$ and the purified SPL exhibited a single band at $\sim 40$ $\mathrm{kDa}$ (Figure 1). A typical yield for such a SPL purification process is $\sim 40 \mathrm{mg}$ protein per liter of LB media. 


\section{Iron-sulfur content in SPL}

The presence of the [4Fe-4S] cluster in SPL was confirmed by the iron-sulfur content analysis. The as-isolated SPL was found to contain 3.1 iron and 2.9 sulfur atoms per protein; these numbers increase to 3.8 iron and 3.7 sulfur atoms after cluster re-constitution. These numbers further support the conclusion that SPL harbors a [4Fe-4S] cluster in its holoenzyme form.

\section{Spectroscopic characterization of purified SPL}

The as-isolated SPL protein exhibited a typical UV absorption of a $[4 \mathrm{Fe}-4 \mathrm{~S}]^{2+}$ species with a shoulder at $420 \mathrm{~nm}$, suggesting that the majority of the protein-harbored clusters survived during the protein purification process (Figure 2). The UV absorption at $420 \mathrm{~nm}$ increased slightly after cluster reconstitution $(\sim 10 \%)$, suggesting that more $[4 \mathrm{Fe}-4 \mathrm{~S}]^{2+}$ cluster was restored back into the protein. The absorption was bleached quickly upon addition of sodium dithionite due to the formation of the $[4 \mathrm{Fe}-4 \mathrm{~S}]^{1+}$ cluster (Figure 2). As expected, the reduced cluster destabilizes the protein; a prolonged $(1 \mathrm{~h})$ incubation at ambient temperature led to a partial precipitation of the SPL protein. ${ }^{50}$

\section{EPR characterization of the reduced cluster in SPL}

After dithionite reduction, the resulting $[4 \mathrm{Fe}-4 \mathrm{~S}]^{1+}$ cluster in SPL is EPR active and exhibits an $S=1 / 2$ signal that is similar to that of other members of the radical SAM superfamily, such as pyruvate formate lyase activating enzyme ${ }^{51}$ (Figure 3 ). Simulation yields $\mathbf{g}=$ [2.030(5), 1.930(5), 1.895(5)], which is equivalent to the $g$ values reported for this center by other workers. ${ }^{7-9}$ Note that the greater field dispersion of $35 \mathrm{GHz}$ EPR allows resolution of slight rhombic splitting that may not always be resolved in X-band $(\sim 9 \mathrm{GHz})$ studies. $^{9}$

Quantitation of the EPR signal of reduced SPL is complicated by the nature of the rapid passage EPR phenomenon and the lack of a suitable standard. A true $S=1 / 2$ system such as $\mathrm{Cu}$ (II), commonly used as a spin standard, has totally different relaxation behavior than an FeS cluster. The $S=1 / 2$ ground states of $\left[\mathrm{Fe}_{2} \mathrm{~S}_{2}\right]^{+}$and $\left[\mathrm{Fe}_{4} \mathrm{~S}_{4}\right]^{+}$are the result of intricate spin coupling mechanisms that also result in many low lying spin excited states. ${ }^{52-55} \mathrm{We}$ have therefore employed another FeS protein, which was available to us, for EPR intensity comparison with reduced SPL. The protein was Fd1 isolated from Aquifex aeolicus by Meyer and co-workers. ${ }^{56}$ The relaxation behavior of this protein, under identical experimental conditions, is similar to that of reduced SPL, as evidence by the microwave power dependence of their EPR spectra at $2 \mathrm{~K} .{ }^{43}$ At the lowest microwave power for which signals could readily be observed $(\sim 10 \mathrm{~W})$, where saturation effects are minimized, the integrated intensity of a $2 \mathrm{mM}$ solution of A. aeolicus $\mathrm{Fd} 1$ was ten times that of a solution of reduced SPL. This would indicate that the concentration of SPL containing $[4 \mathrm{Fe}-4 \mathrm{~S}]^{+}$cluster was $\sim 200 \mathrm{M}$. Considering the facts that the protein concentration was $400 \mu \mathrm{M}$ and the asisolated SPL contained 3.1 Fe atoms/protein molecule, this data indicates that the $1 \mathrm{~h}$ reduction by dithionite resulted a reduced $[4 \mathrm{Fe}-4 \mathrm{~S}]^{+}$cluster in $\sim 70 \%$ of our SPL samples, contrasting to the $20 \%$ [4Fe-4S] $]^{+}$cluster observed in PFL-AE. ${ }^{57}$ Taking into account the partially precipitated protein during the prolonged dithionite incubation, a close to quantitative reduction of the SPL cluster could be obtained if proper conditions are employed.

\section{$d_{3}-S P T p T(2)$ repair by SPL}

Under the currently hypothesized mechanism, $\mathrm{H}$ atom abstraction from either 6- $\mathrm{H}_{\text {proR }}$ or 6$\mathrm{H}_{\text {pros }}$ position of SP by the 5'-dA radical (Figure 4, pathway A or B) leads to different reaction isotopolog products owing to the fact that only $6-\mathrm{H}_{\text {proS }}$ is labeled by a deuterium in 2. Therefore, analyzing the deuterium distribution in the resulting products should 
subsequently shed light on the SPL mechanism. $5^{\prime}$-dA was isolated and found to exhibit a $[\mathrm{M}+\mathrm{H}]^{+}$signal of 252.2 (calculated 252.15, Figure 5a), implying no deuterium incorporation. The isolated TpT was found to possess a $[\mathrm{M}-\mathrm{H}]^{-}$signal of 548.2 (Figure $6 \mathrm{a})$, corresponding to the formation of $d_{3}-\mathrm{TpT}$. These data suggest that reaction possibly occurred under the pathway A shown in Figure 4; no deuterium was abstracted by 5'-dA radical and all deuterium atoms in SP TpT were retained in the repaired TpT.

\section{$d_{4}-S P T p T(4)$ repair by SPL}

Enzyme repair of $d_{4}$-SP $(4)$ resulted in a $5^{\prime}$-dA species which exhibited a major $[\mathrm{M}+\mathrm{H}]^{+}$ signal at $m / e=253.2$ (Figure 5b), implying that a deuterium was taken from 4 during the enzyme reaction. The isolated 5'-dA also exhibited a minor peak of 252.2 at roughly one fourth the intensity of the 253.2 signal in the mass spectroscopy, indicating presence of some non-deuterated 5'-dA. However, surprisingly the isolated TpT was found to possess a $[\mathrm{M}-\mathrm{H}]^{-}$signal at $m / e=548.2$ (Figure 6b), corresponding to the formation of $d_{3}-\mathrm{TpT}$. This result could be reached via two possibilities: (1) A similar reaction as shown in Figure 4 occurred here as well. However, a large isotope effect was involved in the $\mathrm{H}$ atom backdonation step between the 5'-dA and the TpT radical, leading to the formation of a small amount of $d_{4}$-TpT and a majority of $d_{3}$-TpT. The ESI-MS signal of $d_{4}$-TpT was obscured by the second isotopic peak of the $d_{3}$-TpT and thus escaped detection. (2) A different reaction occurred; the deuterium abstracted from $\mathbf{4}$ was not returned to TpT after enzyme catalysis.

\section{TpT analysis by high resolution ESI-MS}

To test if a large kinetic isotope effect (KIE) occurs in the H back-donation step, we redetermined the mass of the resulting TpT out of the $\mathbf{4}$ repair by high resolution mass spectroscopy. As shown in Figure 6c, the first two isotope peaks exhibit mass of 548.1482 and 549.1511 respectively, corresponding to the first two peaks of $d_{3}$-TpT species (Calc: 548.1479 and 549.1509 respectively). According to the Agilent MassHunter software, such an isotopic distribution suggests the presence of a single $d_{3}$-TpT species with a $99 \%$ certainty, and furthermore, the software was able to automatically calculate the correct formula of the $d_{3}$-TpT species with an error of $0.6 \mathrm{ppm}$. No obvious mass peak was detected around $m / e=549.1536$, the calculated mass for the first isotope peak of $d_{4}$-TpT compound. Moreover, the observed abundance of the second isotope peak was $21.91 \%$ of the first one, which is only slightly lower than the theoretical value $(23.81 \%)$ for a $d_{3}$-TpT compound. If $d_{4}$-TpT was produced and co-eluted with $d_{3}$-TpT on HPLC, then the ratio between the second/first isotope peaks should be increased. We therefore conclude that it is very unlikely that there was any detectable $d_{4}$-species present in the isolated $d_{3}$-TpT.

\section{SP TpT (1) repair by SPL in $\mathrm{D}_{2} \mathrm{O}$ buffer}

If a large KIE is not involved, then the abstracted deuterium must be exchanged by a protium during the catalysis. As the most likely protium source in enzyme reaction is the aqueous buffer, we therefore tested if an $\mathrm{H}$ atom from the water was incorporated into the repaired TpT. The SP TpT (1) repair was conducted in a buffer containing $\sim 98 \%$ of $\mathrm{D}_{2} \mathrm{O}$. As expected, the isolated TpT was found to possess a $[\mathrm{M}-\mathrm{H}]^{-}$signal at $m / e=546.2$ (Figure 6e), corresponding to the formation of $d_{1}$-TpT. In contrast, the reaction in $\mathrm{H}_{2} \mathrm{O}$ resulted regular TpT, with a $[\mathrm{M}-\mathrm{H}]^{-}$signal at $m / e=545.2$ (Figure 6d). This observation suggests that a proton from the original SP TpT was exchanged with solvent; thus the reaction pathway represented by Figure 4 was not correct and a solvent exchangeable proton must be involved in enzyme catalysis. 


\section{$d_{3}$-SP TpT (3) repair by SPL}

As shown in Chart 1, the differences between compounds $\mathbf{2}$ and $\mathbf{4}$ are: (1) A deuterium occupies the $6-\mathrm{H}_{\text {pros }}$ position in $\mathbf{2}$ and the 6- $\mathrm{H}_{\text {proR }}$ position in compound 4. (2) Compound 2 possesses a $\mathrm{CD}_{2}$ linker and a $\mathrm{CH}_{3}$ moiety while $\mathbf{4}$ has a $\mathrm{CH}_{2}$ linker and a $\mathrm{CD}_{3}$ moiety. The repair of $d_{4}$-SP TpT (4) suggests that a deuterium was abstracted by the 5 '-dA radical during the SPL mediated repair. To exclude the possibility that the abstracted deuterium was from the $\mathrm{CD}_{3}$ moiety but not from the $6-\mathrm{H}_{\mathrm{proR}}$ in 4 , a $d_{3}-\mathrm{SP} \mathrm{TpT}(3)$ which possesses a $\mathrm{CD}_{3}$ moiety but two protium atoms on the $\mathrm{C} 6$ carbon (Chart 1) was utilized for the SPL reaction. After a 20-minute enzyme reaction, the LC-MS analyses of the products found that the isolated 5'-dA showed $m / e=252.2\left(\right.$ from $[\mathrm{M}+\mathrm{H}]^{+}$) and the repaired TpT $m / e=548.2$ (from $[\mathrm{M}-\mathrm{H}]^{-}$), with the isotopic patterns identical to what were shown in Figure 5a and 6a respectively. This finding implies that, as expected, the methyl group did not participate in the enzyme reaction; all three deuterium atoms were therefore retained in the resulting TpT. Thus, the deuterium abstracted from 4 must be from the $6-\mathrm{H}_{\text {proR }}$ position. The fact that no deuterium abstraction from the 6- $\mathrm{H}_{\text {pros }}$ position of $\mathbf{2}$ was observed also suggests that the SPL enzyme abstracts the $\mathrm{H}$ atom with an exclusive stereoselectivity.

\section{Reaction rate and isotope effect determination}

The SP repair rates with substrates $\mathbf{1}, \mathbf{2}$ and $\mathbf{4}$ were determined based on the appearance of $\mathrm{TpT}$ in the HPLC chromatographs as illustrated by Figure 7. The formation rate of 5'-dA was also calculated. The SPL reactions were quenched by $\mathrm{HCl}$ within the first 3 minutes for compound $\mathbf{1}$ and $\mathbf{2}$ and 10 minutes for compound $\mathbf{4}$ to ensure that both $5^{\prime}$-dA and TpT formation were within the linear region. The resulting 5'-dA and TpT peaks in the HPLC chromatographs were integrated and the integrations plotted against reaction time. Using the HPLC calibration curve generated with authentic $5^{\prime}$-dA and TpT, the formation rates of these two species were calculated and are shown in Table 1.

The $K_{m}$ for SP TpT is found to be below $30 \mu \mathrm{M}$ although the value was not accurately determined due to the slow reaction rate and the instability of the enzyme during the elongated reactions. The $K_{m}$ for SP TpT was reported to be $6 \mu \mathrm{M}$ by Fontecave and coworkers, ${ }^{8}$ which is in reasonable agreement with our finding. To ensure that the rates reported in Table 1 reflect the $V_{\max }$, the substrate concentration was maintained at $\sim 100$-fold of the enzyme concentration and at least 100-fold of $K_{m}$. Doubling substrate concentration or decreasing its concentration by half did not change the reaction rates, suggesting that the enzyme was saturated and the rates determined truly represented the $V_{\text {max }}$.

Examination of Table 1 indicates that both $\mathrm{TpT}$ and $5^{\prime}$-dA were formed at almost identical rates regardless of whether $\mathbf{1}$ or $\mathbf{2}\left(d_{3}\right.$-SP TpT) was used as the enzyme substrate, suggesting that protium abstraction occurred in both cases. Such an observation again suggests that it is the protium at the $6-\mathrm{H}_{\text {proR }}$ position of $\mathbf{2}$ that was abstracted by SPL to initiate the repair reaction. The repair rate of $\mathbf{2}$ was thus not examined in $\mathrm{D}_{2} \mathrm{O}$ reaction as a nearly identical rate to that of $\mathbf{1}$ is expected. Both TpT and 5'-dA were found to form at decreased reaction rates when $d_{4}$-SP TpT (4) was utilized as the enzyme substrate. Comparing the rates of $\mathrm{TpT}$ formation yields a primary KIE of $2.9 \pm 0.3$ (Figure 8 ). The formation of $5^{\prime}$-dA was also slowed when $\mathbf{4}$ was used; however care has to be taken before any conclusion can be drawn due to two reasons: (1) The $5^{\prime}-\mathrm{dA}$ is a $d_{1} / d_{0}$ mixture as indicated by the presence of 252.1 peak in Figure $5 \mathrm{~b}$; (2) The $5^{\prime}$-dA observed is likely to be a reaction intermediate; its formation rate does not reflect the property of the overall enzyme reaction (see discussion below).

Changing the buffer from $\mathrm{H}_{2} \mathrm{O}$ to $\mathrm{D}_{2} \mathrm{O}$ has little effect on the reaction rates, as shown in Table 1, suggesting no significant solvent isotope effect is associated with the SPL reaction. 
Furthermore, the primary KIE was unchanged in $\mathrm{D}_{2} \mathrm{O}$ as well. Contrasting to the $d_{3}$-TpT species ([M $-\mathrm{H}]^{-}$signal at 548.2) obtained from the $d_{4}$-SP TpT (4) repair in $\mathrm{H}_{2} \mathrm{O}$ buffer, LC-MS analysis of the yielded TpT in $\mathrm{D}_{2} \mathrm{O}$ reaction revealed a dominant $[\mathrm{M}-\mathrm{H}]^{-}$signal at 549.2 , suggesting a solvent deuterium was incorporated into the TpT, making it a $d_{4}$ species. ${ }^{43}$ This observation complements the previous results in the repair of $\mathbf{1}$ in $\mathrm{D}_{2} \mathrm{O}$ buffer, confirming the involvement of an exchangeable proton in SPL catalysis.

\section{SPL reaction in the absence of excess reductant}

The observed 1:1.7 ratio between 5'-dA and TpT formed during the first two minutes of 1 repair seems to suggest that SAM plays a catalytic role, with SAM regenerated after each catalytic cycle. ${ }^{58}$ As suggested by Scheme 3, regeneration of SAM returns an electron to the iron-sulfur cluster, reducing it to the +1 oxidation state and making it ready for the next catalytic cycle. This rationale suggests that a SPL enzyme with an $\left[\mathrm{Fe}_{4} \mathrm{~S}_{4}\right]^{+}$cluster should be able to catalyze multiple turnovers, similar to what was observed for lysine 2,3-

aminomutase (LAM). ${ }^{59}$ We therefore reduced the iron-sulfur cluster in SPL by dithionite for $0.5 \mathrm{hr}$ and removed the excess reductant via a desalting column. Upon addition of 2-3 times of SAM and substrate 1, the pre-reduced SPL remained active for $3 \mathrm{hrs}$, catalyzing more than 10 turnovers (Figure 9A). This observation is in line with that found in the previous SPL studies, ${ }^{11}$ suggesting that SAM is truly catalytic. The pre-reduced enzyme is only slightly less active than that in the presence of excess dithionite especially in the first 15 minutes of the reaction; a similar observation was also made in LAM studies. ${ }^{59}$

\section{5'-dA generation}

As shown in Figures 7 and 8, a linear formation of 5'-dA was observed in the first two minutes of the reaction. A prolonged reaction however revealed that the $5^{\prime}$-dA formation gradually slowed down and reached its maximum at about 15 minutes (Figure 9B). Surprisingly, after 15 minutes, the amount of 5'-dA observed in the acid-quenched reaction gradually decreased and fell into the basal level in $\sim 1 \mathrm{hr}$. In radical SAM enzymes, $5^{\prime}$-dA is often observed as a side product from the abortive SAM cleavage reaction. ${ }^{10,13,60,61}$ Such a product should accumulate in the solution, resulting in an increase in the amount of 5'-dA observed during the course of the reaction. The observed increase-first-followed-bydecrease pattern in Figure 9B is highly unusual in radical SAM reactions, suggesting that the $5^{\prime}$-dA observed is not the abortive product, but a true reaction intermediate. The fact that $\mathrm{TpT}$ formation remains linear in the first 15 minutes of the reaction followed by a gradual slow-down, with only a very small amount of TpT being formed after $1 \mathrm{hr}$, suggests that the formation of 5'-dA and TpT are concerted processes, further supporting this conclusion.

Furthermore, a lack of 5'-dA formation was often observed when DTT was omitted in SPL reaction; formation of $\mathrm{TpT}$ was however unaffected. This observation further supports the conclusion that SAM is possibly regenerated in SPL reaction. It also appears to suggest that the presence of DTT may slow down this regeneration process, enabling trapping of 5'-dA as a reaction intermediate. However, the SAM regeneration and/or 5'-dA formation seem to be controlled by other factors as well, which we do not fully understand at this point. For instance, the protein preparation seems also to affect the amount of $5^{\prime}$-dA generated in the reaction; protein purified in air generated much more $5^{\prime}$-dA than protein purified anaerobically. Further work is needed to decipher this intriguing SAM regeneration process.

\section{No deuterium incorporation into SAM}

Although SAM seems regenerated after each SPL catalytic cycle, LC-MS analysis of the isolated SAM exhibits a MS signal at $m / e=399.2$ (calculated 399.15) regardless of the SP TpT substrates employed. ${ }^{43}$ Although 5 '-dA radical is proved to abstract the deuterium from the $6-\mathrm{H}_{\text {proR }}$ position of 4 , after 6 enzyme turnovers in the presence of 1.5 -fold of SAM, there 
was still no obvious deuterium incorporation into SAM. This result contradicts an observation in the previous tritium labeling experiment. ${ }^{11}$ Interestingly in LAM where SAM also appears regenerated after each catalytic cycle, no deuterium transfer from lysine to SAM was observed either, ${ }^{45}$ although a more sensitive tritium transfer experiment revealed $\sim 1-6 \%$ of tritium incorporation from the lysine substrate into SAM when large excess of SAM was adopted. ${ }^{46}$

\section{Discussion}

\section{Protein expression and purification}

It is known that co-expression of iron-sulfur proteins with a pDB1282 plasmid which encodes a set of $E$. coli proteins involved in iron-sulfur cluster biogenesis increases the yield of the soluble protein by facilitating cluster incorporation into the newly synthesized apoprotein. ${ }^{21,37,62}$ The incorporated cluster serves as a structural scaffold to help the protein fold correctly, therefore increasing the yield of the soluble portion during expression. The pDB1282 was therefore introduced into SPL expression and the yield of soluble SPL at least doubled. ${ }^{43}$ The resulting SPL exhibits the highest activity among the SPL enzymes purified to date when dinucleotide SP is used as substrate, ${ }^{6,8}$ highlighting the importance of cluster incorporation to the enzyme activity.

\section{Substrate preparation and enzyme activity assays}

The dinucleotide SP TpT substrate can be prepared via organic synthesis as shown by Begley and co-workers. ${ }^{42}$ Among the four SP TpTs shown in Chart 1, two of them, compounds $\mathbf{1}$ and $\mathbf{3}$ can be readily synthesized via this route. However, such a method is not suitable to synthesize the selectively labeled compounds $\mathbf{2}$ and $\mathbf{4}$, as the synthesis includes a hydrogenation step which is catalyzed by $\mathrm{Rh} / \mathrm{Al}_{2} \mathrm{O}_{3}$, resulting in the addition of $\mathrm{H}_{2}$ to the $\mathrm{C}=\mathrm{C}$ bond from either side of the thymine plane. Thus, if $\mathrm{D}_{2}$ is used in hydrogenation, the resulting SP will be a mixture of two configurational isomers with deuterium occupying either the $6-\mathrm{H}_{\text {proR }}$ or $6-\mathrm{H}_{\text {pros }}$ position. Such a mixture cannot be separated via chromatographic means, and thus cannot provide any useful mechanistic information.

In contrast, photoreaction has proved a reliable means to prepare SP substrate with exclusive stereoselectivity. ${ }^{17}$ Due to the nature of this process, SP can be generated only via a solid phase reaction which restricts the thermal motion and conformational change of TpT so that only thymine residues adopting the "right" conformation dimerize, while the vast majority of excited molecules are thermally quenched. ${ }^{63}$ Thus deuterated SP is obtained at only $0.1-$ $0.4 \%$ yields depending on whether a primary deuterium isotope effect is encountered in photoreaction. However, despite the low yields, the stereoselectively labeled SP compounds $\mathbf{2}$ and $\mathbf{4}$ can be readily produced by this photochemical means.

Although our purified SPL enzyme exhibits the highest activity $\left(0.35 \pm 0.03 \mathrm{~min}^{-1}\right)$ with 1 as the enzyme substrate, ${ }^{6,8}$ the reaction is still slow probably due to the weak binding affinity of this minimally sized dinucleotide substrate to the enzyme. In contrast, with a SPcontaining GGTTGG hexamer or an SP-containing plasmid DNA, the SP repair rate increased 50 to 500 times due to the improved substrate binding. ${ }^{7,11}$ Our SPL reaction rate is also comparable with other known radical SAM enzymes characterized to date. ${ }^{26,37,64,65}$

\section{SPL mechanism - $\mathrm{H}$ atom abstraction by $5^{\prime}-\mathrm{dA}$ radical}

The reductive cleavage of SAM generates a 5'-dA radical, which abstracts an 6-H atom from $\mathrm{SP}$ to form $5^{\prime}$-dA. Analysis of the $5^{\prime}$-dA isotopomers/isotopologs that result from use of selectively labeled substrates $\mathbf{2}$ and $\mathbf{4}$ provides the most direct evidence to reveal which of the $\mathrm{C} 6 \mathrm{H}$-atoms is abstracted during the reaction. 
As shown in Figure 5, when 2, which contains a deuterium at the 6- $\mathrm{H}_{\text {pros }}$ position, was used for the SPL reaction, a protium was abstracted by the $5^{\prime}$-dA radical. In contrast, the abstracted atom was a deuterium when 4 , which contains a deuterium at the $6-\mathrm{H}_{\text {proR }}$ position, was used. The fact that a protium was again abstracted when $\mathbf{3}$, which contains a $\mathrm{CD}_{3}$ group but two $\mathrm{C} 6$ protiums, was employed firmly supports the proposal that the abstracted $\mathrm{H}$ atom is from the $\mathrm{C} 6$ carbon. Taken together, these results clearly demonstrate that SPL abstracts the 6- $\mathrm{H}_{\text {proR }}$ atom, leaving a $\mathrm{C} 6$ radical behind to initiate the SP repair process.

The equation shown in Scheme 1 is often used to illustrate the reactions of SP formation and repair in literature. ${ }^{8,9}$ Such an equation seems to imply that the SP repair catalyzed by SPL is a simple reverse process of SP photo-formation. Our observations prove that this assumption is overly simplistic. As described in Scheme 2, an $\mathrm{H}$ atom from the $\mathrm{CH}_{3}$ moiety of the $3^{\prime}-\mathrm{T}$ migrates to the $6-\mathrm{H}_{\text {pros }}$ position in the $\mathrm{SP}$ formation and the original $\mathrm{H}$ atom at the $\mathrm{C} 6$ of $5^{\prime}-\mathrm{T}$ remains on that carbon, becoming the $6-\mathrm{H}_{\text {proR }}$ atom of SP. ${ }^{17}$ In contrast, the migrated atom becomes the 6-HproR during the enzyme repair; while 6- $\mathrm{H}_{\mathrm{proS}}$ subsequently becomes the $\mathrm{C} 6$ proton in the repaired thymine.

Such a conclusion also rationalizes part of the observations previously made by Broderick and co-workers. ${ }^{11}$ In their experiments, tritium was incorporated into either the methyl or the $\mathrm{C} 6$ carbon of thymine. Our photochemical studies show that labeling the $-\mathrm{CH}_{3}$ moiety of thymine would result in tritium incorporation into the $6-\mathrm{H}_{\text {pros }}$ position of SP; while labeling the thymine $\mathrm{C} 6$ carbon would incorporate tritium into the $6-\mathrm{H}_{\text {proR }}$ position. The SPL enzyme abstracts the 6- $\mathrm{H}_{\text {proR }}$ atom, leaving behind the 6- $\mathrm{H}_{\mathrm{proS}}$ atom at the $\mathrm{C} 6$ carbon of repaired 5'-thymine. Therefore, in the previous study, although the SP $6-\mathrm{H}_{\text {proS }}$ could bear a tritium originating from the $-\mathrm{CH}_{3}$ moiety of thymine before the photoreaction, that atom was not abstracted and had no chance to enter the catalytic cycle of SP repair. In contrast, the tritium at the thymine $\mathrm{C} 6$ carbon migrated to the $6-\mathrm{H}_{\text {proR }}$ position of SP, and was then abstracted by the $5^{\prime}$-dA radical to initiate the SP repair process. Thus, the stereoselectivity in $\mathrm{H}$ atom abstraction was reflected in Broderick's earlier work as well; however it was not recognized due to a lack of full understanding of SP photochemistry at that time.

The primary KIE of $2.9 \pm 0.3$ exhibited by the SPL reaction suggests that the $\mathrm{H}$ atom abstraction mediated by the $5^{\prime}$-dA radical is involved in the enzyme rate-determining steps. The presence of this relatively large KIE further confirms the stereo configuration assignment that the abstracted $\mathrm{H}$ atom is from the $6-\mathrm{H}_{\text {proR }}$ position. As expected, the formation of 5'-dA was slowed down as well owing to this KIE when $\mathbf{4}$ was employed for SPL reaction.

\section{SPL mechanism - $\mathrm{H}$ atom back donation}

Comparing with the radical initiation step, our results on the $\mathrm{H}$ atom back-donation step are quite surprising. The current reaction mechanism predicts the $\mathrm{H}$ atom abstracted by the 5'$\mathrm{dA}$ radical would be donated back to the repaired TpT, however the abstracted deuterium from 4 was not returned. Carefully analyzing the MS isotopic pattern of the resulting TpT excludes the possible involvement of large KIE; while the deuterium incorporation from the $\mathrm{D}_{2} \mathrm{O}$ buffer into TpT strongly suggests that the TpT radical takes an $\mathrm{H}$ atom from an unknown source which is able to exchange proton with the buffer.

Although these results are inconsistent with an earlier work, ${ }^{11}$ they do agree with an observation by Fontecave and co-workers. ${ }^{10}$ By employing a SAM molecule with a deuterated methylene moiety, they found no evidence for those deuterium atoms to be transferred into the resulting TpT. This result, together with ours, suggests that no direct $\mathrm{H}$ atom exchange occurs between the $5^{\prime}$-dA and TpT radical. Recently the cysteine 141 residue 
of the SPL from Bacillus strains has drawn much attention due to its potential involvement in SPL catalysis. ${ }^{10,66}$ Distinct from the cysteines in the CXXXCXXC SAM motif, the C141 residue does not participate in the $[4 \mathrm{Fe}-4 \mathrm{~S}]$ cluster formation and subsequent SAM redox chemistry. However, mutation of this residue to alanine in B. subtilis abolished the SPL activity, leading to cell death under UV radiation with a similar efficiency as mutations of cysteine residues involved in the SAM motif. ${ }^{66}$ Fontecave and co-workers revisited this mutation in an in vitro enzymology study and found that instead of forming $\mathrm{TpT}$, the mutant yielded a TpT-SO $\mathrm{S}_{2}$ molecule as the major repair product, which was generated through a reaction between the $\mathrm{TpT}$ radical and dithionite, the reductant added to reduce the $[4 \mathrm{Fe}-4 \mathrm{~S}]]^{2+}$ cluster to initiate the SPL reaction. ${ }^{10}$ Although the role of C141 is not clearly defined to date, the formation of TpT-SO $\mathrm{S}_{2}$ strongly indicates that this residue is associated with the $\mathrm{H}$ atom back-donation step of the enzymatic reaction.

Using the cysteine residue as the $\mathrm{H}$ atom donor (instead of the $5^{\prime}-\mathrm{dA}$ ) is more reasonable considering the different bond strengths involved. A calculation predicts the $\mathrm{C}-\mathrm{H}$ bond dissociation energy (BDE) of 5'-dA to be $12.2 \mathrm{kcal} / \mathrm{mol}$ higher than that for the methyl moiety of thymine $(98.2 \mathrm{vs} 86.0 \mathrm{kcal} / \mathrm{mol})$; in contrast, the BDE of the $\mathrm{S}-\mathrm{H}$ bond in cysteine is suggested to be around $82 \mathrm{kcal} / \mathrm{mol} ;{ }^{67,68}$ which is line with other computational results that indicate the allylic $\mathrm{C}-\mathrm{H}$ bond to be $\sim 3-4 \mathrm{kcal} / \mathrm{mol}$ stronger than the $\mathrm{S}-\mathrm{H}$ bond in a thiol compound like methylthiol ${ }^{69,70}$ It is therefore logical for SPL to use the cysteine S-H moiety instead of the $\mathrm{C}-\mathrm{H}$ bond of $5^{\prime}$-dA as the direct $\mathrm{H}$-atom donor, greatly lowering the energy barrier for this $\mathrm{H}$-atom back-transfer step.

The involvement of the cysteine residue also solves the space problem raised by the current mechanism. ${ }^{67}$ The current mechanism requires $5^{\prime}$-dA to be associated with both $\mathrm{H}$-atom transfer steps. The first step involves the $5^{\prime}$-dA radical and the $6-\mathrm{H}_{\text {proR }}$ on the $5^{\prime}$-thymine residue of SP. Should the resulting 5'-dA donate the $\mathrm{H}$ atom back to the thymine allyl radical at the $3^{\prime}$ end of the SP, it has to move down one nucleoside, roughly 3-4 Á vertical distance. This movement requires a major protein conformational change, which is unfavorable in energy. ${ }^{67}$ In contrast, such a conformational change is no longer necessary should the cysteine residue serve as the $\mathrm{H}$-atom donor; all the $\mathrm{H}$ atom transfer steps involved in catalysis can be readily accommodated within the protein framework.

The $\mathrm{H}$ atom back-transfer step from the cysteine to the thymine allyl radical is unlikely to be involved in the enzyme rate-limiting steps, as indicated by the absence of a solvent isotope effect. The unchanged KIE exhibited by SPL reaction in $\mathrm{D}_{2} \mathrm{O}$ buffer also supports this conclusion.

\section{SPL mechanism - SAM regeneration}

The results from the SAM regeneration step are also surprising. In the previous studies, the conclusion of SAM regeneration was drawn after the tritrium label was found to be transferred from the SP into SAM. ${ }^{11}$ However, examining the isolated SAM from SPL reaction with 1.5-fold SAM and 6-fold deuterated substrate $\mathbf{4}$ found no apparent deuterium incorporation even after all the SP substrate was consumed. This result supports the hypothesis of SAM regeneration but SAM may not be regenerated via a simple one-step reaction as shown in Scheme 3.

In radical SAM enzymes, the ratio of 5'-dA to product is of significance. A $1: 1$ ratio implies SAM serves as a co-substrate as one molecule of substrate modified consumes one molecule of SAM, while a $1: X(X>>1)$ ratio suggests SAM serves as a co-factor as only a catalytic amount is needed. ${ }^{58}$ As revealed in Figure 9B, the ratio between $5^{\prime}$-dA and TpT produced after a 2 -hr reaction is greater than $1: 500$. This observation further supports a catalytic role for SAM, suggesting SAM to be regenerated at the end of each catalytic cycle. 
Carefully examining the SPL reaction reveals that although 5'-dA was observed in the early stage of the reaction; these $5^{\prime}$-dA molecules were not accumulating in the solution. This observation suggests that the $5^{\prime}$-dA observed in the quenched reaction is actually a true reaction intermediate on the way to SAM regeneration, not the abortive product of the uncoupled SAM cleavage reaction as commonly observed in other radical SAM enzymes. ${ }^{10,13,60,61}$ Furthermore, the amount of $5^{\prime}$-dA observed appears to be coupled to the rate of $\mathrm{TpT}$ formation, further supporting our conclusion. The observed $5^{\prime}$-dA formation rate is always smaller than that of TpT formation, suggesting that the assumption of $5^{\prime}$-dA is the faster step in enzyme catalytic cycle. Therefore, these 5'-dA molecules are kinetically competent to serve as reaction intermediate as well.

When a thiol containing compound such as DTT is removed from the reaction system, the $\mathrm{TpT}$ formation seems to be relatively undisturbed, however the amount of 5'-dA observed often decreases into the basal level. The fact that $5^{\prime}$-dA formation can be disturbed by other processes such as protein purification clearly suggests that the $5^{\prime}$-dA formation/SAM regeneration is likely to be more complex than currently thought and more work is needed before this process is understood.

The putative $\mathrm{H}$-atom back transfer from the $\mathrm{C} 141$ residue to the thymine methyl radical yields a thiyl radical, which thus must be involved in the SAM regeneration process. The simplest model to accommodate it is to insert this cysteine residue between the thymine allyl radical and 5'-dA in the reaction pathway. However, as rationalized above, the thiyl radical is more stable than the allylic radical in thymine, which makes the direct $\mathrm{H}$-atom transfer from $5^{\prime}$-dA to the cysteine thiyl radical even more unfavorable thermodynamically. Even so, a similar reaction was proposed in class II ribonucleotide reductase (RNR), ${ }^{71}$ where the catalytic thiyl radical does abstract an $\mathrm{H}$ atom back from $5^{\prime}$-dA to regenerate a $5^{\prime}$-dA radical. This $5^{\prime}$ - $\mathrm{dA} \bullet$ subsequently recombines with the $\mathrm{Cob}(\mathrm{II})$ alamin species to regenerate the adenosylcobalamin. Such a reaction is suggested to proceed via a concerted mechanism: the un-favored $\mathrm{H}$ atom abstraction by the thiyl radical is coupled with the formation of a stable C-Co bond in adenosylcobalamin, providing an energy offset for the former process. ${ }^{71}$ As the SAM formation from $5^{\prime}$-dA and methionine is also heavily favored thermodynamically, ${ }^{72,73}$ coupling the $\mathrm{H}$ atom abstraction by the thiyl radical with the SAM regeneration process may provide a explanation for the SPL reaction as well.

Although it is possible for the single cysteine residue to regenerate SAM, if cysteine is the only protein residue involved, then one should expect production of a significant amount of abortive product $5^{\prime}$-dA under competition of DTT, should the reaction site be ready accessible to this small molecule. The fact that little abortive $5^{\prime}$-dA was generated in the presence of DTT suggests that the enzyme possesses some kind of "error-prevention" function. Such a function is difficult to achieve by a single cysteine and is more likely to be realized via the involvement of other amino acid residues. Taken together, our data suggests that there may be a cysteine-containing electron-transfer pathway involved in SAM regeneration, which possibility will be tested in future studies.

\section{Newly Hypothesized SPL mechanism}

All of these findings imply that the original mechanistic hypothesis for SPL ${ }^{11}$ needs to be refined by including protein residues in the enzyme catalysis. We therefore tentatively propose a modified mechanism as shown in Figure 10. After the reductive SAM cleavage reaction with an electron provided by the $[4 \mathrm{Fe}-4 \mathrm{~S}]^{1+}$ cluster, the resulting $5^{\prime}$-dA radical abstracts the 6- $\mathrm{H}_{\mathrm{proR}}$ atom to yield the SP radical on the C6 carbon. Subsequent fragmentation of SP leads to the formation of a delocalized methyl radical on the $3^{\prime}$-T. Instead of abstracting an $\mathrm{H}$ atom back from the $5^{\prime}$ - $\mathrm{dA}$, the TpT radical draws an $\mathrm{H}$ atom from an unidentified protein residue, with the C141 the most likely candidate, to yield the 
repaired $\mathrm{TpT}$. The resulting thiyl radical on this cysteine could abstract an $\mathrm{H}$ atom back from $5^{\prime}$-dA; or it may oxidize its neighboring residue(s) to generate another protein radical species before it reacts with $5^{\prime}$-dA. Recombination of the $5^{\prime}$-dA radical and the methionine regenerates SAM at the end of each catalytic cycle.

One problem posed by this mechanism is to explain the tritium interchange between $5^{\prime}$-dA radical (SAM) and thymine substrate observed by Broderick and co-workers. ${ }^{9,11}$ A recent observation made by Eguchi and co-workers in their studies of BtrN suggested that the hydrogen atom abstraction step between the $5^{\prime}$-dA radical and the enzyme substrate is reversible. ${ }^{65}$ Such a reversible $\mathrm{H}$ atom interchange step was proposed by Liu and co-workers in their studies of DesII as well. ${ }^{26}$ If a similarly reversible step is involved between $5^{\prime}$-dA radical and the SP substrate as shown in Figure 9, the tritium exchange observed between 5'dA radical (SAM) and thymine can also be rationalized. Additionally, no data was shown on how much tritium was exchanged between the reaction partners in the radio-labeling experiments. ${ }^{9,11}$ As scintillation counting is a relatively sensitive method, a rather low percentage of tritium incorporation can be detected.

The immediate task to firmly establish the hypothesized reaction mechanism is to confirm that the cysteine 141 indeed functions as the $\mathrm{H}$ atom donor. The radical intermediates involved in the reaction pathway may also be trapped and characterized via similar approaches conducted by Frey and co-workers in their mechanistic studies of LAM. ${ }^{74}$ These experiments as well as a search for possible protein residues that may participate in the SAM regeneration process are currently in progress.

\section{Supplementary Material}

Refer to Web version on PubMed Central for supplementary material.

\section{Acknowledgments}

The authors thank Professor Eric Long at IUPUI for helpful discussions, the National Institute of Environmental Health Sciences (R00ES017177) as well as IUPUI startup funds for financial support. The NMR and MS facilities at IUPUI are supported by National Science Foundation MRI grants CHE-0619254 and DBI-0821661, respectively. We thank Professor Brian M. Hoffman, Northwestern University, for use of the $35 \mathrm{GHz}$ EPR spectrometer, which is funded by NSF grant MCB-0316038. We thank Prof. Jacques Meyer, CEA-Grenoble, France, for providing samples of reduced Aquifex aeolicus Fd1. We thank Prof. Squire J. Booker, the Pennsylvania State University, for the generous gift of plasmid pDB1282.

\section{References}

(1). Prescott, LM.; Harley, JP.; Klein, DA. Microbiology. 6th ed.. McGraw-Hill Higher Education; Dubuque, IA: 2005.

(2). Nicholson W, Munakata N, Horneck G, Melosh H, Setlow P. Microbiol. Mol. Biol. Rev. 2000; 64:548. [PubMed: 10974126]

(3). Setlow P. Environ. Mol. Mutagen. 2001; 38:97. [PubMed: 11746741]

(4). Setlow P. Annu. Rev. Microbiol. 1988; 42:319. [PubMed: 3059997]

(5). Desnous CL, Guillaume D, Clivio P. Chem. Rev. 2010; 110:1213. [PubMed: 19891426]

(6). Silver S, Chandra T, Zilinskas E, Ghose S, Broderick W, Broderick J. J. Biol. Inorg. Chem. 2010; 15:943. [PubMed: 20405152]

(7). Pieck J, Hennecke U, Pierik A, Friedel M, Carell T. J. Biol. Chem. 2006; 281:36317. [PubMed: 16968710]

(8). Chandor A, Berteau O, Douki T, Gasparutto D, Sanakis Y, Ollagnier-De-Choudens S, Atta M, Fontecave M. J. Biol. Chem. 2006; 281:26922. [PubMed: 16829676]

(9). Buis J, Cheek J, Kalliri E, Broderick J. J. Biol. Chem. 2006; 281:25994. [PubMed: 16829680] 
(10). Chandor-Proust A, Berteau O, Douki T, Gasparutto D, Ollagnier-De-Choudens S, Fontecave M, Atta M. J. Biol. Chem. 2008; 283:36361. [PubMed: 18957420]

(11). Cheek J, Broderick J. J. Am. Chem. Soc. 2002; 124:2860. [PubMed: 11902862]

(12). Mehl RA, Begley TP. Org. Lett. 1999; 1:1065. [PubMed: 10825958]

(13). Rebeil R, Nicholson WL. Proc. Natl. Acad. Sci. 2001; 98:9038. [PubMed: 11470912]

(14). Donnellan JE Jr. Setlow RB. Science. 1965; 149:308. [PubMed: 17838105]

(15). Cadet, J.; Vigny, P. Bioorganic Photochemistry: Photochemistry and the Nucleic Acids. Vol. 1. Wiley; New York: 1990. The photochemistry of nucleic acids; p. 1

(16). Mantel C, Chandor A, Gasparutto D, Douki T, Atta M, Fontecave M, Bayle PA, Mouesca JM, Bardet M. J. Am. Chem. Soc. 2008; 130:16978. [PubMed: 19012397]

(17). Lin G, Li L. Angew. Chem. Int. Ed. 2010; 49:9926.

(18). Marsh ENG, Patterson DP, Li L. ChemBioChem. 2010; 11:604. [PubMed: 20191656]

(19). Frey PA, Hegeman AD, Ruzicka FJ. Crit. Rev. Biochem. Mol. Biol. 2008; 43:63. [PubMed: 18307109]

(20). Sofia HJ, Chen G, Hetzler BG, Reyes-Spindola JF, Miller NE. Nucl. Acids Res. 2001; 29:1097. [PubMed: 11222759]

(21). Chatterjee A, Li Y, Zhang Y, Grove TL, Lee M, Krebs C, Booker SJ, Begley TP, Ealick SE. Nat. Chem. Biol. 2008; 4:758. [PubMed: 18953358]

(22). Paraskevopoulou C, Fairhurst SA, Lowe DJ, Brick P, Onesti S. Mol. Microbio. 2006; 59:795.

(23). Walsby CJ, Ortillo D, Yang J, Nnyepi MR, Broderick WE, Hoffman BM, Broderick JB. Inorg. Chem. 2005; 44:727. [PubMed: 15859242]

(24). Vey JL, Drennan CL. Chem. Rev. 2011; 111:2487. [PubMed: 21370834]

(25). Ruszczycky MW, Choi S-H, Liu H-W. J. Am. Chem. Soc. 2010; 132:2359. [PubMed: 20121093]

(26). Szu P-H, Ruszczycky MW, Choi S-H, Yan F, Liu H-W. J. Am. Chem. Soc. 2009; 131:14030. [PubMed: 19746907]

(27). Mulder DW, Boyd ES, Sarma R, Lange RK, Endrizzi JA, Broderick JB, Peters JW. Nature. 2010; 465:248. [PubMed: 20418861]

(28). Okada Y, Yamagata K, Hong K, Wakayama T, Zhang Y. Nature. 2010; 463:554. [PubMed: 20054296]

(29). Driesener R, Challand M, Mcglynn S, Shepard E, Boyd E, Broderick J, Peters J, Roach P. Angew. Chem. Int. Ed. 2010; 49:1687.

(30). Grove TL, Ahlum JH, Sharma P, Krebs C, Booker SJ. Biochem. 2010; 49:3783. [PubMed: 20377206]

(31). Yan F, Lamarre JM, Roî̀Hrich R, Wiesner J, Jomaa H, Mankin AS, Fujimori DG. J. Am. Chem. Soc. 2010; 132:3953. [PubMed: 20184321]

(32). Wecksler SR, Stoll S, Tran H, Magnusson OT, Wu S-P, King D, Britt RD, Klinman JP. Biochem. 2009; 48:10151. [PubMed: 19746930]

(33). Grove TL, Lee K-H, Clair J, Krebs C, Booker SJ. Biochem. 2008; 47:7523-7538. [PubMed: 18558715]

(34). Frey PA, Magnusson OT. Chem. Rev. 2003; 103:2129-2148. [PubMed: 12797826]

(35). Farrar CE, Siu KKW, Howell PL, Jarrett JT. Biochem. 2010; 49:9985. [PubMed: 20961145]

(36). Grove TL, Benner JS, Radle MI, Ahlum JH, Landgraf BJ, Krebs C, Booker SJ. Science, ASAP.

(37). Cicchillo RM, Iwig DF, Jones AD, Nesbitt NM, Baleanu-Gogonea C, Souder MG, Tu L, Booker SJ. Biochem. 2004; 43:6378. [PubMed: 15157071]

(38). Bradford MM. Anal. Biochem. 1976; 72:248. [PubMed: 942051]

(39). Gill SC, Von Hippel PH. Anal. Biochem. 1989; 182:319. [PubMed: 2610349]

(40). Fish WW. Methods Enzymol. 1988; 158:357. [PubMed: 3374387]

(41). Beinert H. Anal. Biochem. 1983; 131:373. [PubMed: 6614472]

(42). Kim SJ, Lester C, Begley TP. J. Org. Chem. 1995; 60:6256.

(43). see supporting information.

(44). Iwig DF, Booker SJ. Biochem. 2004; 43:13496. [PubMed: 15491157] 
(45). Aberhart DJ. J. Chem. Soc. Perkin Trans. 1. 1988:343.

(46). Kilgore JL, Aberhart DJ. J. Chem. Soc. Perkin Trans. 1. 1991:79.

(47). Werst MM, Davoust CE, Hoffman BM. J. A. Chem. Soc. 1991; 113:1533.

(48). Mailer C, Taylor CPS. Biochim. Biophys. Acta. 1973; 322:195. [PubMed: 4358082]

(49). Belford, RL.; Nilges, MJ. EPR Symposium, 21st Rocky Mountain Conference Denver; Colorado. 1979; August.

(50). Ugulava NB, Gibney BR, Jarrett JT. Biochem. 2001; 40:8343. [PubMed: 11444981]

(51). Cheek J, Krebs C, Huynh B, Broderick J. J. Inorg. Biochem. 2001; 86:176.

(52). Bertrand P. Inorg. Chem. 1993; 32:741.

(53). Bertrand P, Gayda J-P, Fee JA, Kuila D, Cammack R. Biochim. Biophys. Acta. 1987; 916:24. [PubMed: 2822125]

(54). Bertrand P, Guigliarelli B, More C. New. J. Chem. 1991; 15:445.

(55). Bertrand P, More C, Guigliarelli B, Fournel A, Bennett B, Howes B. J. Am. Chem. Soc. 1994; 116:3078.

(56). Meyer J, Clay MD, Johnson MK, Stubna A, Munck E, Higgins C, Wittung-Stafshede P. Biochem. 2002; 41:3096. [PubMed: 11863449]

(57). Henshaw TF, Cheek J, Broderick JB. J Am. Chem. Soc. 2000; 122:8331.

(58). Marsh E, Patwardhan A, Huhta M. Bioorg. Chem. 2004; 32:326. [PubMed: 15381399]

(59). Lieder KW, Booker S, Ruzicka FJ, Beinert H, Reed GH, Frey PA. Biochem. 1998; 37:2578. [PubMed: 9485408]

(60). Duschene KS, Broderick JB. FEBS Lett. 2010; 584:1263. [PubMed: 20176015]

(61). Padovani D, Thomas F, Trautwein AX, Mulliez E, Fontecave M. Biochem. 2001; 40:6713. [PubMed: 11389585]

(62). Kriek M, Peters L, Takahashi Y, Roach PL. Protein Express. Purif. 2003; 28:241.

(63). Schreier WJ, Schrader TE, Koller FO, Gilch P, Crespo-Hernandez CE, Swaminathan VN, Carell T, Zinth W, Kohler B. Science. 2007; 315:625. [PubMed: 17272716]

(64). Ballinger MD, Reed GH, Frey PA. Biochem. 1992; 31:949. [PubMed: 1310425]

(65). Yokoyama K, Numakura M, Kudo F, Ohmori D, Eguchi T. J Am. Chem. Soc. 2007; 129:15147. [PubMed: 18001019]

(66). Fajardo-Cavazos P, Rebeil R, Nicholson W. Curr. Microbiol. 2005; 51:331. [PubMed: 16163454]

(67). Guo J, Luo Y, Himo F. J. Phys. Chem. B. 2003; 107:11188.

(68). Himo F. BBA-Bioenerg. 2005; 1707:24.

(69). S. Jursic B. J. Chem. Soc., Perkin Trans. 2. 1999:369.

(70). Blanksby SJ, Ellison GB. Acc. Chem. Res. 2003; 36:255. [PubMed: 12693923]

(71). Lawrence CC, Stubbe J. Curr. Opin. Chem. Biol. 1998; 2:650. [PubMed: 9818192]

(72). Wang SC, Frey PA. Trends Biochem. Sci. 2007; 32:101. [PubMed: 17291766]

(73). Wang SC, Frey PA. Biochem. 2007; 46:12889. [PubMed: 17944492]

(74). Frey PA. Annu. Rev. Biochem. 2001; 70:121. [PubMed: 11395404] 


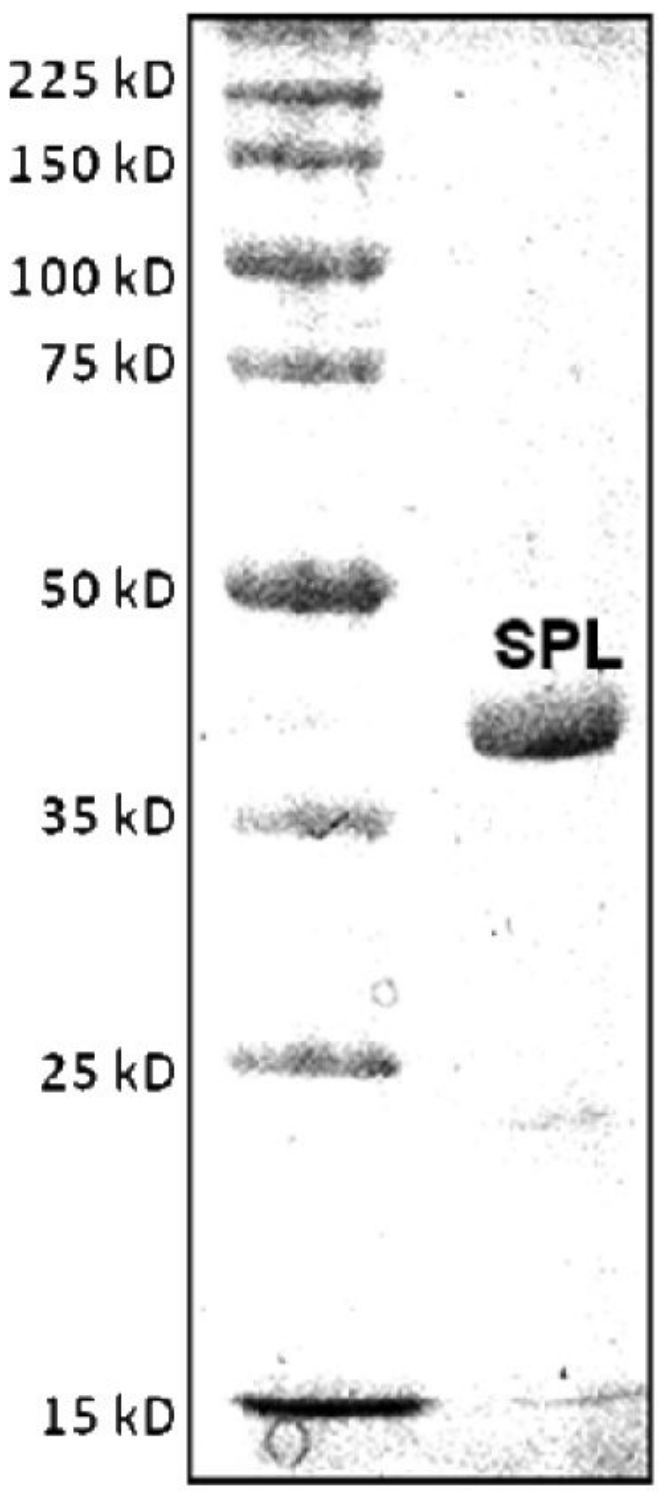

Figure 1.

The SDS-PAGE gel of the SPL protein overexpressed from E. coli and purified via Ni-NTA chromatography. 

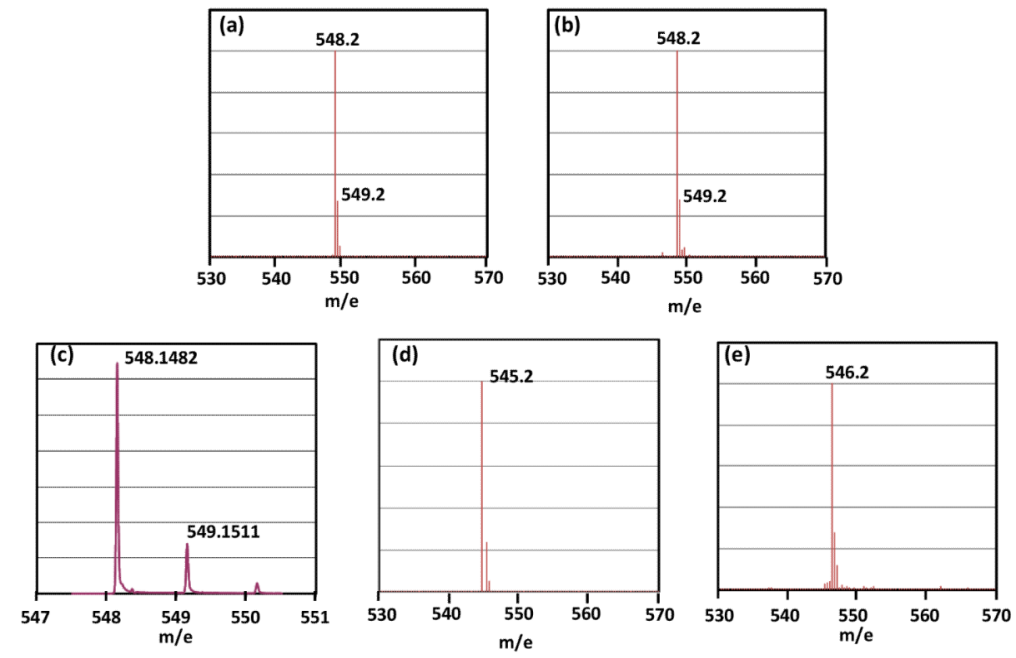

Figure 2.

UV-visible absorption spectra of the [4Fe-4S] cluster in SPL at the as-isolated form (solid line) and the reduced form (dashed line). For both spectra, 50 M SPL protein was utilized in a $25 \mathrm{mM}$ Tris buffer containing $300 \mathrm{mM} \mathrm{NaCl}, 10 \%$ glycerol, at $\mathrm{pH} 7.0$. For the reduced protein, the reduction was conducted by $2 \mathrm{mM}$ dithionite for $20 \mathrm{~min}$ before the spectrum was taken. The spectra were recorded in a UV cuvette with a $1 \mathrm{~cm}$ path length under anaerobic conditions at room temperature. 


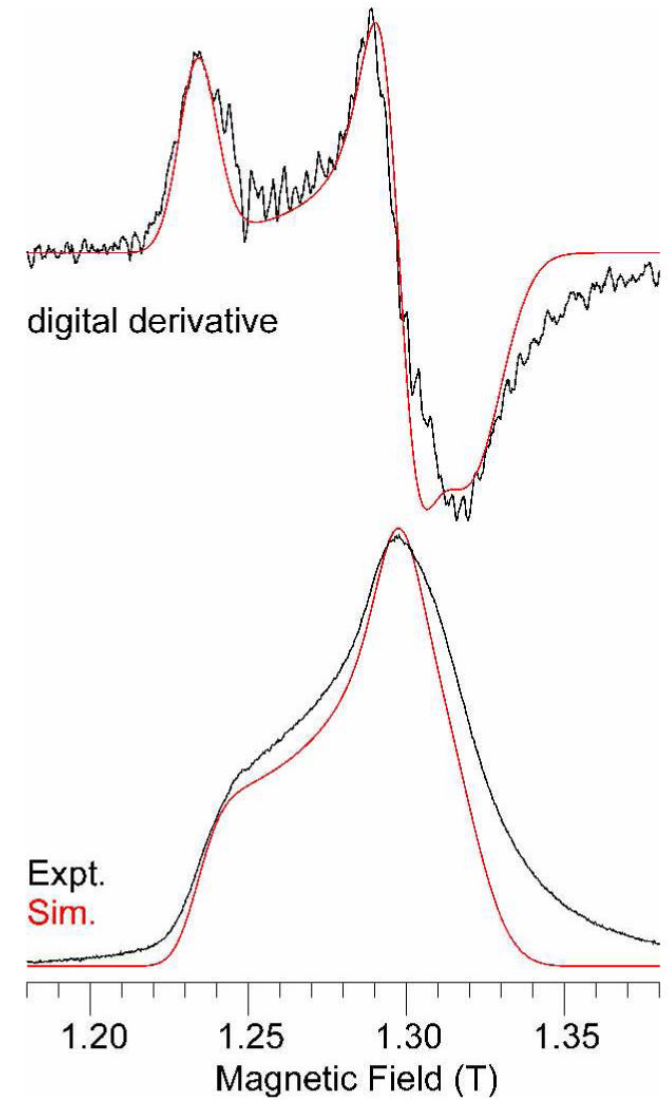

Figure 3.

$35 \mathrm{GHz}$ EPR spectrum of dithionite-reduced SPL ( $0.4 \mathrm{mM})$. Experimental spectrum (black trace): temperature, $2 \mathrm{~K}$; microwave frequency, $35.063 \mathrm{GHz}$; microwave power, $100 \mu \mathrm{W}$ (30 $\mathrm{dBm}) ; 100 \mathrm{kHz}$ field modulation amplitude, $1.0 \mathrm{G}$; time constant, $8 \mathrm{~ms}$; scan time, $30 \mathrm{~s}$; average of 4 scans. Simulated spectrum (red trace): $S=1 / 2, \mathbf{g}=[2.030,1.930,1.895]$; single crystal Gaussian linewidths, $W=[200,180,300] \mathrm{MHz}$ (half-width at half-maximum). The lower pair of traces are present the absorption lineshape, as experimentally observed under "rapid passage" conditions; the upper pair of traces are digital first derivatives to provide a more familiar EPR presentation. The "tailing" seen at high field may be due to relaxation effects in passage and not to actual spectral intensity. 


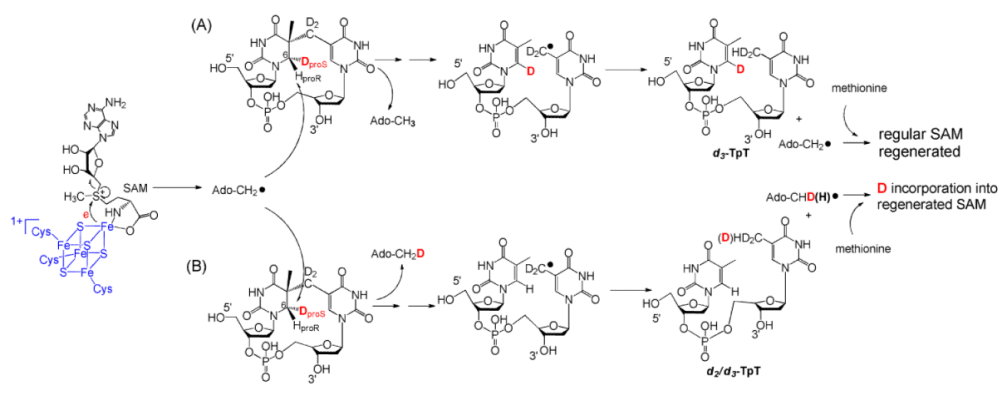

Figure 4.

Using $d_{3}$-SP TpT (2) as the enzyme substrate to illustrate the expected reaction products according to the current SPL mechanism shown in Scheme 3. (A): The 5'-dA radical abstracts the protium at the $6-\mathrm{H}_{\text {proR }}$ position to initiate the reaction. All three deuterium atoms in compound $\mathbf{2}$ should be retained in the repair product TpT; thus $d_{3}$-TpT as well as regular 5'-dA and SAM are expected after the reaction. (B): The 5'-dA radical abstracts the deuterium at the $6-\mathrm{H}_{\text {pros }}$ position to initiate the reaction. Correspondingly, a deuterium is incorporated into the resulting $5^{\prime}$-dA and $d_{2} / d_{3}$-TpT and $d_{1} / d_{0}$-SAM mixtures are expected by the end of the reaction due to the $\mathrm{H}$ or $\mathrm{D}$ abstraction from the methyl group of 5'-dA by the $\mathrm{TpT}$ radical in the $\mathrm{H}$ atom back donation step. 


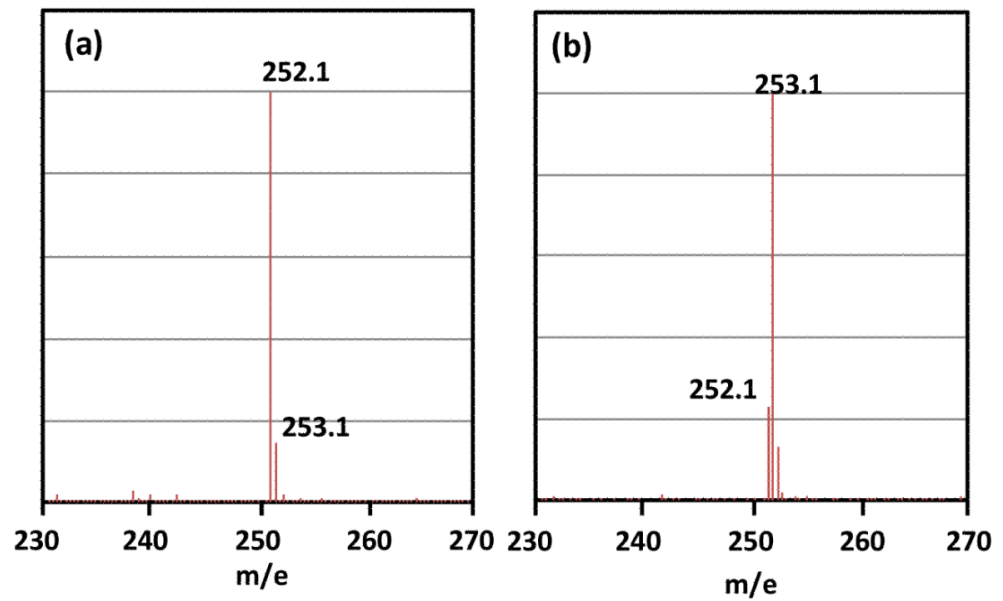

Figure 5.

(a) $[\mathrm{M}+\mathrm{H}]^{+}$signal of the $5^{\prime}-\mathrm{dA}$ isolated out of the SPL reaction with the $d_{3}$-SP TpT (2) which contains a deuterium at the $6-\mathrm{H}_{\text {pros }}$ position as the enzyme substrate, the 252.1 signal suggests that no deuterium was incorporated into the $5^{\prime}$-dA. (b) $[\mathrm{M}+\mathrm{H}]^{+}$signal of the $5^{\prime}$-dA isolated with $d_{4}$-SP TpT (4) which contains a deuterium at the $6-\mathrm{H}_{\text {proR }}$ position as the enzyme substrate. The observed 253.1 signal suggests that a deuterium atom was incorporated into the $5^{\prime}-\mathrm{dA}$. 

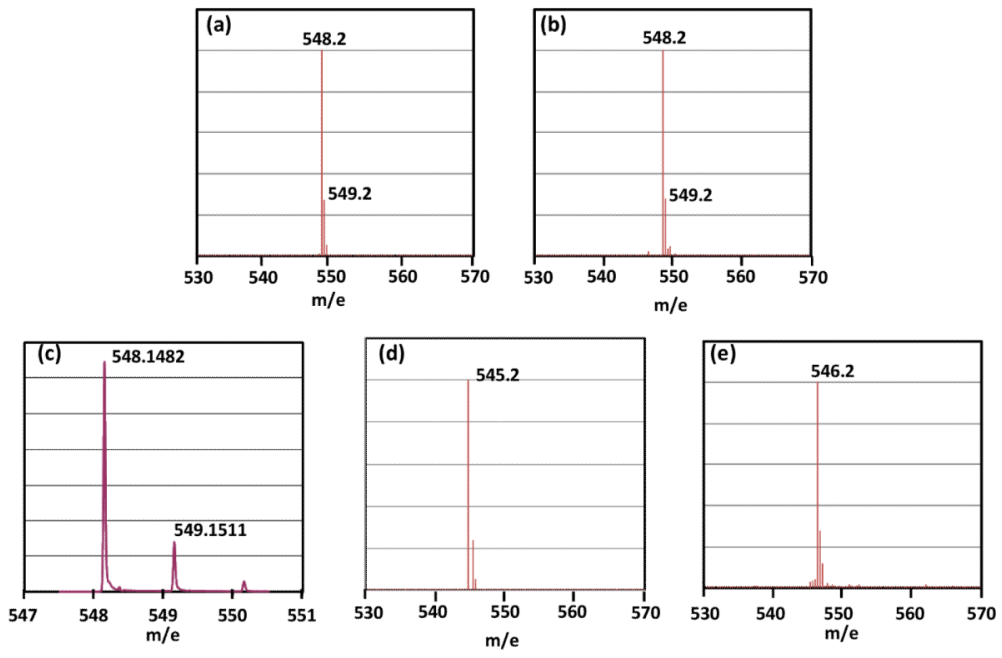

Figure 6.

(a) The $[\mathrm{M}-\mathrm{H}]^{-}$signal of the TpT isolated in the $d_{3}$-SP TpT (2) reaction, the detected 548.2 signal suggests that all three deuterium atoms in SP were transferred into the formed TpT. (b) The $[\mathrm{M}-\mathrm{H}]^{-}$signal of the TpT isolated in the $d_{4}$-SP TpT (4) reaction. The detected 548.2 signal suggests either a large isotope effect in the $\mathrm{H}$ atom back-donation step or a loss of one deuterium during the catalysis. (c) The high-resolution ESI-MS of the TpT generated from the enzyme repair of 4 . The formation of a sole $d_{3}$-TpT species was suggested by the detected isotopic peak distributions. (d) The $[\mathrm{M}-\mathrm{H}]^{-}$signal of the TpT isolated with regular $\mathrm{SP}(\mathbf{1})$ as the enzyme substrate in $\mathrm{H}_{2} \mathrm{O}$ buffer. (e) The $[\mathrm{M}-\mathrm{H}]^{-}$signal of the TpT isolated with 1 as substrate in $98 \% \mathrm{D}_{2} \mathrm{O}$ buffer. The $+1 \mathrm{MS}$ signal observed in (e) relative to that in (d) clearly suggests the incorporation of a deuterium from the $\mathrm{D}_{2} \mathrm{O}$ buffer into the formed $\mathrm{TpT}$. 


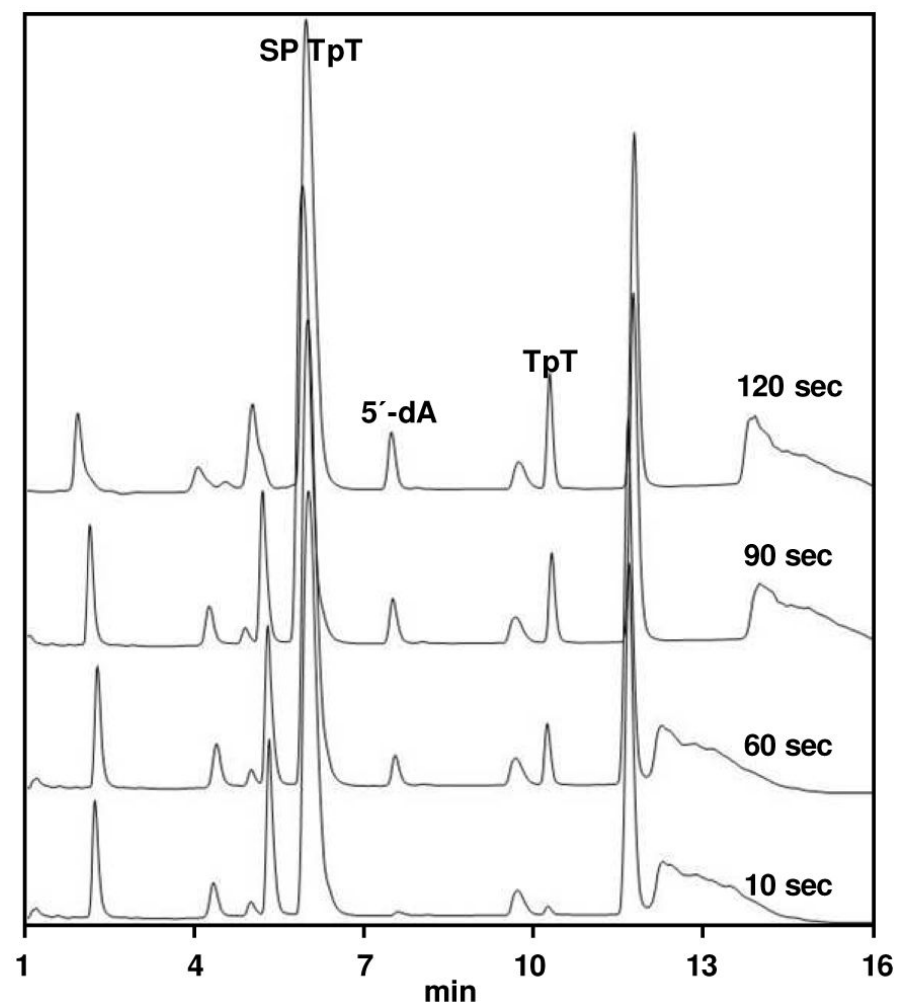

Figure 7.

HPLC chromatograph of the SP TpT (1) repair mediated by SPL in the first two minutes of reaction. SP TpT was eluted at $6.0 \mathrm{~min}, 5^{\prime}$-dA at $7.8 \mathrm{~min}$, and $\mathrm{TpT}$ at $10.2 \mathrm{~min}$. 

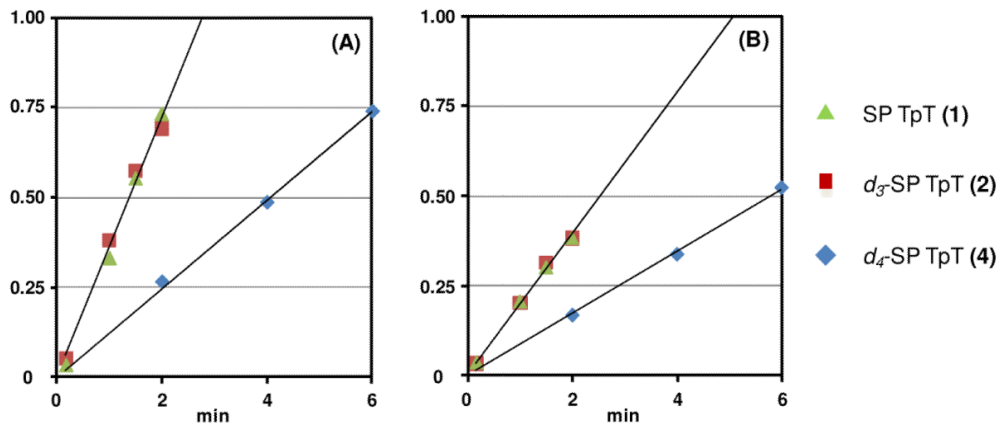

Figure 8.

Determination of the $V_{\max }$ based on the formation of TpT (A) and 5'-dA (B) in SPL catalyzed dinucleotide SP TpT repair. Enzyme reaction rates were calculated via plotting the amount of $\mathrm{TpT}$ isolated versus reaction time. The primary kinetic isotope effect (KIE) for SPL reaction was determined to be $2.9 \pm 0.3$ by comparing the rates of $\mathrm{TpT}$ formation shown in plot A. 

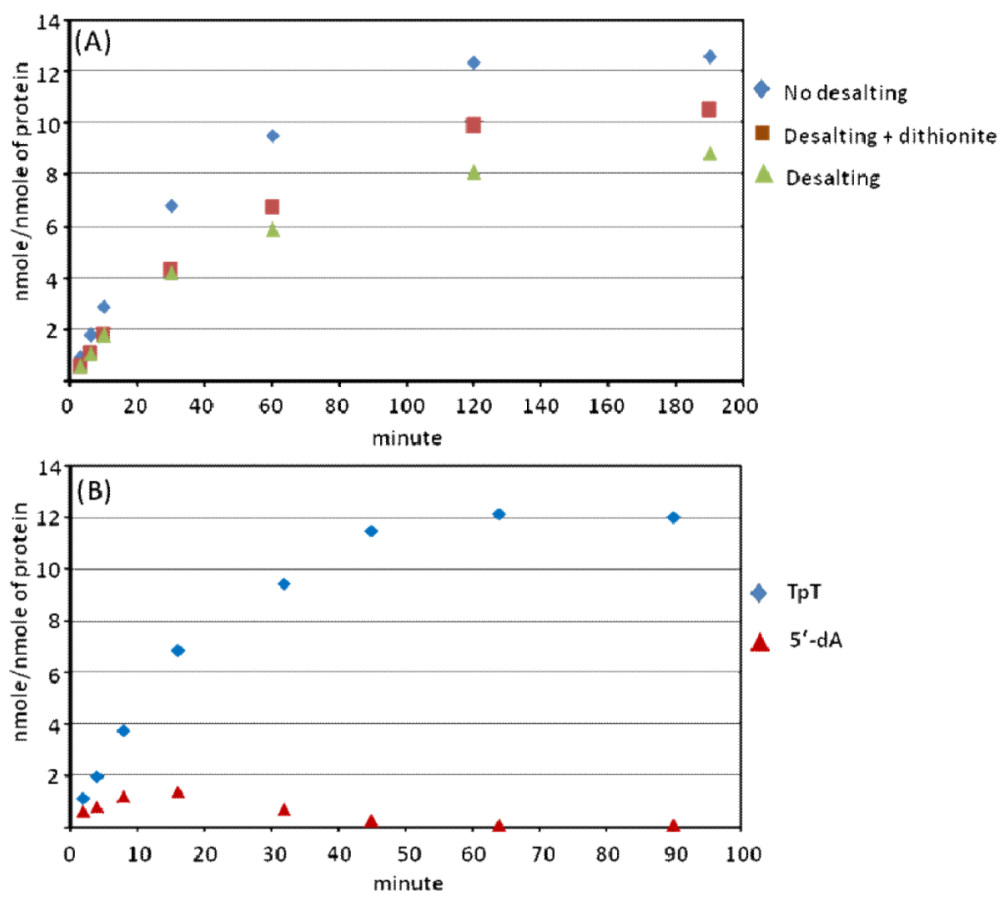

\section{Figure 9.}

(A) Formation of TpT during a 3-hr SP repair reaction. Reaction was conducted under normal conditions: After cluster reconstitution, the reaction was initiated by $1 \mathrm{mM}$ dithionite. After cluster reconstitution, the enzyme was pre-reduced by $1 \mathrm{mM}$ dithionite for $0.5 \mathrm{hr}$. The excess inorganic ions were then removed by a desalting treatment. Dithionite was re-supplemented to the resulting protein solution and the reaction initiated by addition of SAM and SP. $\triangle$ After cluster reconstitution, cluster pre-reduction by dithionite and desalting treatment, SP and SAM were added to start the reaction. (B) 5'-dA formation observed in the acid-quenched SPL reaction at various time. The reaction was carried out under normal conditions as described above. 


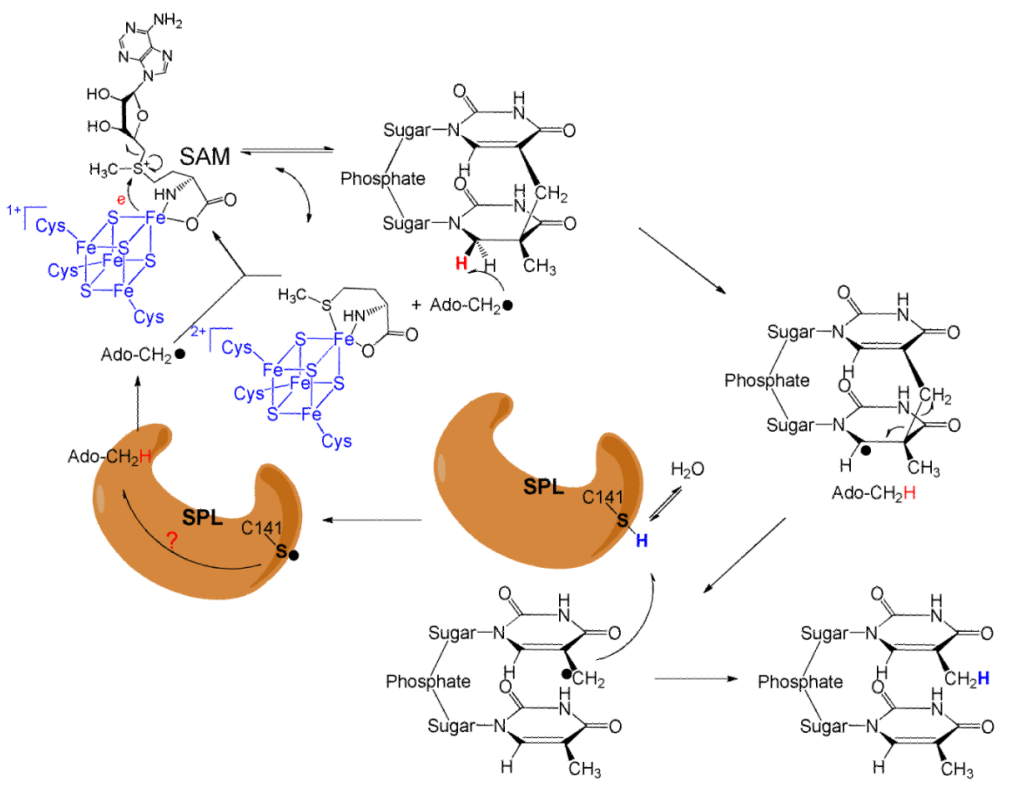

Figure 10.

Newly proposed reaction mechanism for SPL catalyzed SP dimer repair. The 5'-dA radical generated from SAM reductive cleavage reaction takes the $6-\mathrm{H}_{\mathrm{proR}}$ atom to yield a $\mathrm{C} 6$ radical on SP, the SP methylene bridge subsequently undergoes a hemolytic cleavage to give a thymine methyl radical. (Note: This allyl radical is likely to delocalize to the thymine aromatic ring; the current drawing as a methyl radical is a simplified model to facilitate discussion) This radical abstracts an $\mathrm{H}$ atom back from an unknown protein residue, presumably $\mathrm{C} 141$, to generate a thiyl radical, releasing the repaired TpT. This thiyl radical either takes an $\mathrm{H}$-atom back from the 5'-dA directly, or it reacts with other protein residues before the $5^{\prime}-\mathrm{dA}$ is re-oxidized to the radical form again. The resulting 5'-dA radical recombines with methionine to regenerate $\mathrm{SAM}$ and finish one catalytic cycle. 

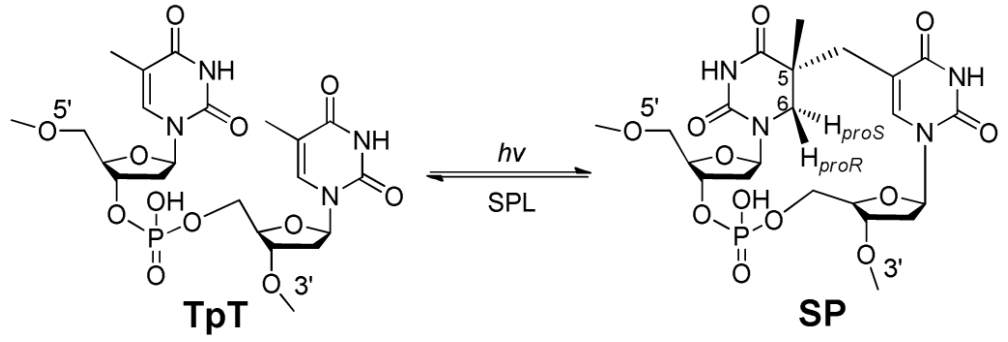

Scheme 1. 

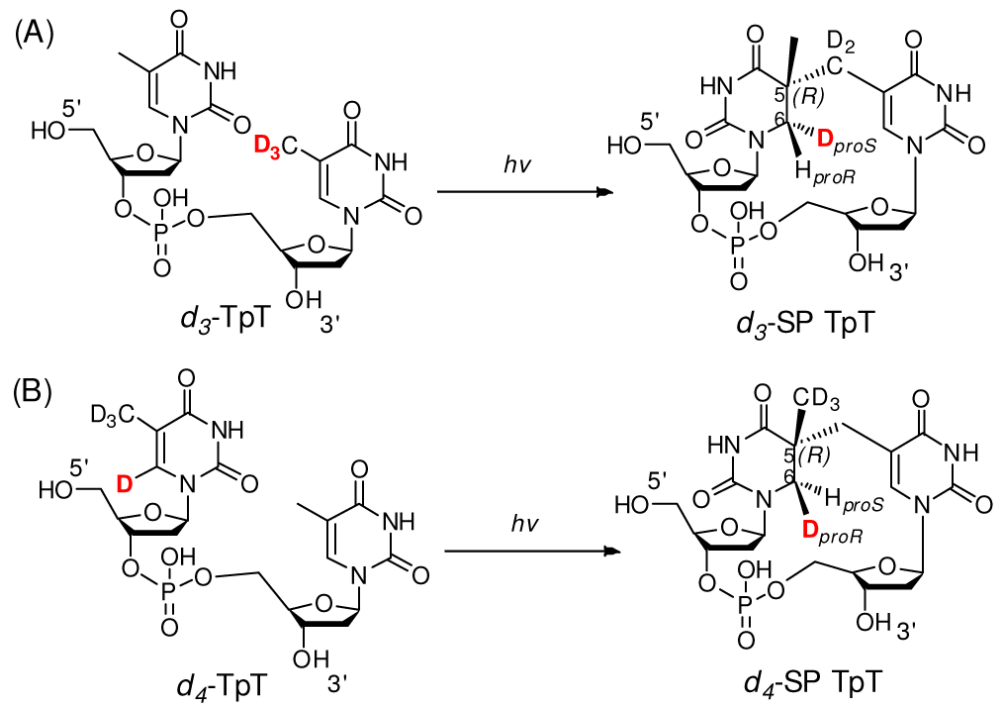

Scheme 2. 


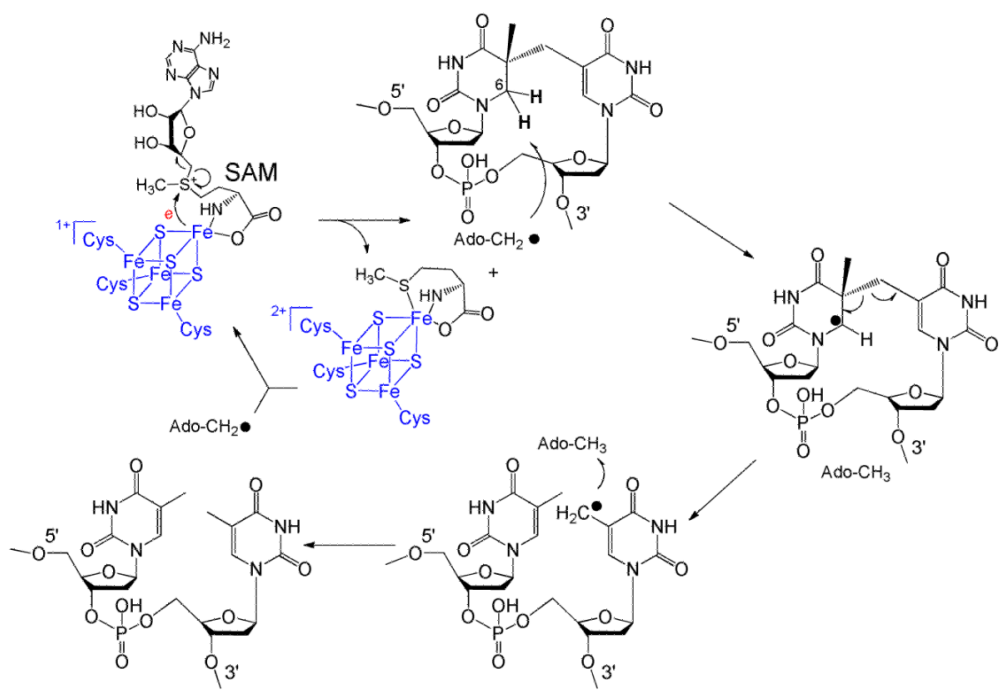

Scheme 3 . 


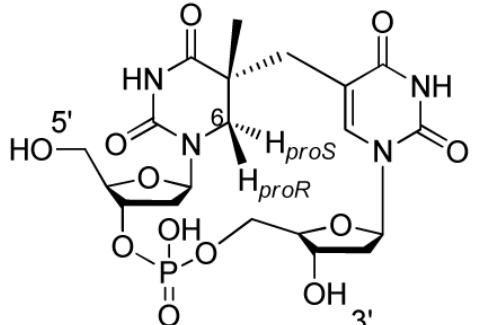

(1)

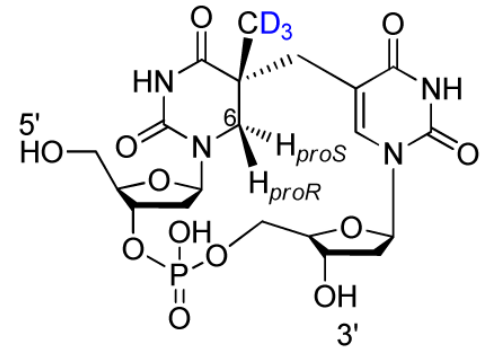

(3)

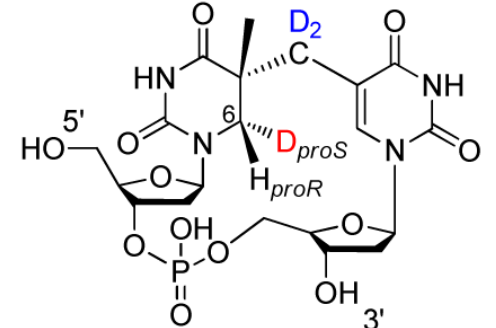

(2)

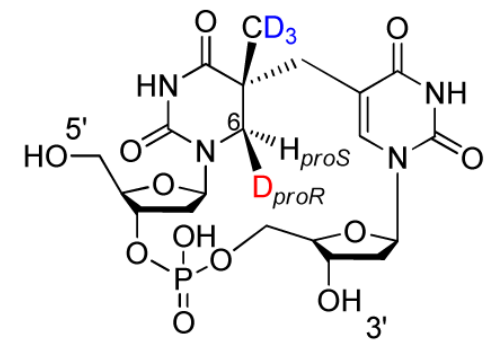

(4)

Chart 1. 
Table 1

The formation rates of $5^{\prime}-\mathrm{dA}$ and $\mathrm{TpT}$ in $\mathrm{SPL}$ catalyzed reaction

\begin{tabular}{|l|c|c|c|}
\hline Substrate used & SP TpT (1) & $\boldsymbol{d}_{\boldsymbol{B}}$-SP TpT (2) & $\boldsymbol{d}_{\boldsymbol{4}}$-SP TpT (4) \\
\hline TpT formation rate in $\mathrm{H}_{2} \mathrm{O}$ buffer $\left(\mathrm{min}^{-1}\right)$ & $0.35 \pm 0.03$ & $0.35 \pm 0.03$ & $0.12 \pm 0.01$ \\
\hline 5'-dA formation rate $\left(\mathrm{min}^{-1}\right)$ in $\mathrm{H}_{2} \mathrm{O}$ buffer & $0.20 \pm 0.02$ & $0.20 \pm 0.02$ & $0.09 \pm 0.01$ \\
\hline TpT formation rate in $\mathrm{D}_{2} \mathrm{O}$ buffer $\left(\mathrm{min}^{-1}\right)$ & $0.34 \pm 0.03$ & N.D. & $0.12 \pm 0.01$ \\
\hline
\end{tabular}

N.D.: not determined 